\title{
Multiple Desensitization Mechanisms of Mechanotransducer Channels Shape Firing of Mechanosensory Neurons
}

\author{
Jizhe Hao and Patrick Delmas \\ Centre de Recherche en Neurobiologie et Neurophysiologie de Marseille, Unité Mixte de Recherche 6231, Centre National de la Recherche Scientifique, \\ Université de la Méditerranée, 13344 Marseille Cedex 15, France
}

\begin{abstract}
How desensitization of mechanotransducer currents regulates afferent signal generation in mammalian sensory neurons is essentially unknown. Here, we dissected desensitization mechanisms of mechanotransducer channels in rat sensory neurons that mediate the sense of touch and pain. We identified four types of mechanotransducer currents that distribute differentially in cutaneous nociceptors and mechanoreceptors and that differ in desensitization rates. Desensitization of mechanotransducer channels in mechanoreceptors was fast and mediated by channel inactivation and adaptation, which reduces the mechanical force sensed by the transduction channel. Both processes were promoted by negative voltage. These properties of mechanotransducer channels suited them to encode the dynamic parameters of the stimulus. In contrast, inactivation and adaptation of mechanotransducer channels in nociceptors had slow time courses and were suited to encode duration of the stimulus. Thus, desensitization properties of mechanotransducer currents relate to their functions as sensors of phasic and tonic stimuli and enable sensory neurons to achieve efficient stimulus representation.
\end{abstract}

\section{Introduction}

In the mammalian somatosensory system, mechanosensory neurons mediate the sense of touch and pain (Basbaum et al., 2009). The peripheral terminals of these neurons, whose cell bodies lie in trigeminal and dorsal root ganglia (DRG), are responsible for the transduction of mechanical stimuli into action potentials (APs) that propagate to the CNS. Each sensory nerve fiber is fine-tuned to respond to distinct mechanical stimuli, including texture, shape, vibration, and pressure, although the molecular basis underlying this functional diversity remains unclear (Tsunozaki and Bautista, 2009).

Mechanosensitive neurons contain low-threshold mechanoreceptors (LTMs), which respond to light touch, vibration, stretch, or internally generated movements, and high-threshold mechanoreceptors (HTMs), which sense noxious levels of pressure. The ability of these cells to detect mechanical cues relies, at least in part, on the presence of mechanotransducer channels that rapidly transform mechanical forces into electrical signals (Lumpkin and Caterina, 2007). Recent studies have established that DRG neurons express several types of mechanosensitive (MS) currents (McCarter et al., 1999; Drew et al., 2002; Hu and Lewin, 2006; McCarter and Levine, 2006). Except for one current

Received June 9, 2010; revised July 27, 2010; accepted July 30, 2010.

This study was supported by the Centre National de la Recherche Scientifique and by grants from the Agence Nationale de la Recherche, Fondation Schlumberger, L'Association pour la Recherche sur le Cancer Inca-2006, Institut UPSA de la Douleur, Institut pour la Recherche sur la Moelle Épinière et l'Encéphale, and Fondation pour la Recherche Médicale. J.H. was supported by a PhD studentship from the French Ministry of Research.

Correspondence should be addressed to Dr. Patrick Delmas, Centre de Recherche en Neurophysiologie et Neurobiologie de Marseille, Unité Mixte de Recherche 6231, Centre National de la Recherche Scientifique, Université de la Méditerranée, CS80011, Boulevard Pierre Dramard, 13344 Marseille Cedex 15, France. E-mail: patrick.delmas@univmed.fr.

DOI:10.1523/JNEUROSCI.2926-10.2010

Copyright $\odot 2010$ the authors $\quad 0270-6474 / 10 / 3013384-12 \$ 15.00 / 0$ described in mouse DRG neurons (Hu and Lewin, 2006), all MS currents characterized so far in rat sensory neurons are carried nonselectively by cations (McCarter et al., 1999; Drew et al., 2002, 2007; McCarter and Levine, 2006; Coste et al., 2007). As with other sensory systems, the molecular identity of the transducer proteins in mammalian mechanosensation remains uncertain. ASIC2,3, TRPV1-4, TRPM8, as well as TRPA1 have been ruled out as likely candidates to mediate these currents (Drew et al., 2004; Wetzel et al., 2007; Rugiero and Wood, 2009).

A common feature of MS currents is their nonstationary behavior in response to a maintained mechanical stimulation. Based on these properties, MS currents have been categorized as rapidly adapting (RA), intermediately adapting (IA), and slowly adapting (SA) currents (Drew et al., 2002). Nonstationary behavior of mechanotransducer currents is a widespread feature in sensory cells. In response to a sustained bundle deflection, hair cell receptor current declines or adapts through closure of transduction channels (Crawford et al., 1989; Ricci et al., 1998; Vollrath et al., 2007). Hair cell adaptation reflects a shift of the currentstimulus relationship, changing the range of displacements to which the transducer channel is sensitive without reducing the maximum response (Holt and Corey, 2000; Fettiplace and Hackney, 2006; Gillespie and Müller, 2009). Functionally, the adaptive shift mechanism serves to preserve hair bundle sensitivity in the face of large stimuli. At variance with hair cells, our understanding of the mechanistic basis and physiological significance of MS channel kinetics in somatosensory neurons remain rudimentary. Recently, it has been proposed that MS current kinetics in DRG neurons is dominated by inactivation instead of adaptation (Rugiero et al., 2010).

A key challenge in mechanosensation is to establish whether mechanotransducer currents are specialized in sensing different 
Table 1. Composition of intracellular solutions

\begin{tabular}{|c|c|c|c|c|c|c|c|c|c|c|}
\hline Solution & BAPTA & EGTA & $\mathrm{CaCl}_{2}$ & Free $\left[\mathrm{Ca}^{2+}\right]_{\mathrm{i}}$ & $\mathrm{MgCl}_{2}$ & MgATP & NaGTP & HEPES & $\mathrm{CsCl}$ & $\mathrm{KCl}$ \\
\hline 1 & 20 & & 0.1 & 1 & 1 & 4 & 0.4 & 10 & 134 & \\
\hline 2 & 20 & & 6.4 & 112 & 1 & 4 & 0.4 & 10 & 124 & \\
\hline 3 & 2 & & 0.01 & 1 & 1 & 4 & 0.4 & 10 & 142 & \\
\hline 4 & & 10 & 0.1 & 1 & 1 & 4 & 0.4 & 10 & 132 & \\
\hline 5 & & 10 & 4.8 & 112 & 1 & 4 & 0.4 & 10 & 125 & \\
\hline 6 & & 10 & 1 & 80 & 1 & 4 & 0.4 & 10 & & 134 \\
\hline
\end{tabular}

Concentrations are expressed in millimolar except for free $\left[\mathrm{Ca}^{2+}\right]_{\mathrm{i}}$ (nM). pH adjusted to 7.3 with $\mathrm{CsOH}$ (Solutions 1-5) or KOH (Solution 6); 297-303 m0sm/L.

mechanical stimuli and shape afferent signal generation. Here, we characterized desensitization properties of mechanotransducer currents in phenotypically identified sensory neurons and showed that desensitization kinetics plays a key role in the strategy of the sensory neuron for discriminating mechanical stimuli.

\section{Materials and Methods}

Dissociation of DRG neurons. Young rats (male Wistar, 120-130 g) were anesthetized with halothane and killed by severing of the carotid arteries in accordance with the Guide for the Care and Use of Laboratory Animals. Dissociation and cultures of DRG neurons were established from thoraco-lumbar DRGs as described previously (Coste et al., 2004; Coste et al., 2007; Maingret et al., 2008). Briefly, DRGs were freed from their connective tissue sheaths and incubated in enzyme solution containing 2 $\mathrm{mg} / \mathrm{ml}$ collagenase IA (Sigma) for $45 \mathrm{~min}$ at $37^{\circ} \mathrm{C}$ and triturated in HBSS (Invitrogen). The resulting suspension was plated in Nunclon dishes coated with $10 \mathrm{ng} / \mathrm{ml}$ laminin (Sigma). Culture medium was DMEM supplemented with $10 \%$ heat-inactivated fetal calf serum, $100 \mathrm{U} / \mathrm{ml}$ penicillin-streptomycin, $2 \mathrm{~mm}$ L-glutamine, $25 \mathrm{ng} / \mathrm{ml}$ nerve growth factor, and $2 \mathrm{ng} / \mathrm{ml}$ glial-derived neurotrophic factor (Invitrogen). Neurons were maintained in a humidified atmosphere $\left(5 \% \mathrm{CO}_{2}, 37^{\circ} \mathrm{C}\right)$ for $12-16$ $\mathrm{h}$ before recording.

Identification of DRG neurons innervating glabrous skin of the hindpaw. 1,1'-dioctadecyl-3,3,3,3' tetramethylindocarbocyanine perchlorate (DiI) was dissolved in DMSO $(170 \mathrm{mg} / \mathrm{ml})$ and diluted $1: 10$ in $0.9 \%$ sterile saline. Five microliters of this solution was injected subcutaneously with an injection needle directed into the epithelium. DiI-labeled neurons were identified under epifluorescence illumination with a Texas Red/rhodamine filter set. Neurons were studied $10-15 \mathrm{~d}$ after injection.

Whole-cell patch-clamp recording. Patch-clamp recordings were performed using borosilicate electrodes having resistances ranging from 2 to 3.5 $\mathrm{M} \Omega$. The standard solution (Table 1, Solution 5) consisted of $125 \mathrm{~mm}$ $\mathrm{CsCl}, 10$ mм HEPES, 0.4 mм NaGTP, 4 mм MgATP, 1 mм $\mathrm{MgCl}_{2}$, $4.8 \mathrm{~mm}$ $\mathrm{CaCl}_{2}$, and $10 \mathrm{~mm}$ EGTA, adjusted to $\mathrm{pH} 7.3$ with $\mathrm{CsOH}$, giving free $\left[\mathrm{Ca}^{2+}\right]_{\mathrm{i}}$ of $112 \mathrm{~nm}$. Pipette solutions in which $\mathrm{CsCl}$ was substituted by $\mathrm{KCl}$ or containing different amounts of the calcium buffers EGTA or BAPTA are listed in Table 1. The standard external solution consisted of the following (in mM): $132 \mathrm{NaCl}, 3 \mathrm{KCl}, 1 \mathrm{MgCl}_{2}, 2.5 \mathrm{CaCl}_{2}, 10 \mathrm{HEPES}$, and $10 \mathrm{D}$-glucose, adjusted to $\mathrm{pH} 7.3$ with $\mathrm{NaOH}(300 \mathrm{mOsm} / \mathrm{L})$. When mentioned, tetrodotoxin (TTX) $(500 \mathrm{~nm})$ was added to the bath solution. The $\mathrm{Ca}^{2+}$-free external solution consisted of the following (in $\mathrm{mm}$ ): 132 $\mathrm{NaCl}, 3 \mathrm{KCl}, 5 \mathrm{MgCl}_{2}, 10 \mathrm{HEPES}$, and 10 D-glucose, adjusted to $\mathrm{pH} 7.3$ with $\mathrm{NaOH}(300 \mathrm{mOsm} / \mathrm{L})$. Cells were superfused using a gravity-fed bath perfusion system at a flow rate of $2 \mathrm{ml} / \mathrm{min}$, while bath solution was removed by continuous suction.

Voltage and current recordings were made using an Axopatch 200B amplifier (Molecular Devices), filtered at $1 \mathrm{kHz}$, and sampled at $40-100$ $\mu$ s. Unless otherwise noted, currents were not leak subtracted. Voltage errors were minimized using $75-85 \%$ series resistance compensation. The access resistance typically ranged from 4.5 to $9 \mathrm{M} \Omega$. Cells for which the access resistance fluctuated after the whole-cell configuration had been attained were not recorded further. Cells showing spontaneous run-up or run-down of MS currents were discarded. Cell capacitance was estimated from the time constant of the decay phase of a current transient elicited by a $10 \mathrm{mV}$ hyperpolarizing step from a holding potential of -60 $\mathrm{mV}$. All experiments were done at room temperature.
Mechanical stimulation. Mechanical stimulation was achieved using a fire-polished glass micropipette cemented to a piezo-electric actuator (Step Driver PZ-100; Burleigh), which was mounted on a micromanipulator. The probe was positioned at an angle of $45^{\circ}$ from horizontal. Downward movement of the probe toward the cell was driven by pClamp program (Molecular Devices). The probe was brought at $1.4 \mu \mathrm{m}$ to the edge of the recorded cell by estimating the distance probe cell using cycling mechanical sweeps of 0.7 or $1.4 \mu \mathrm{m}$. Final adjustment was made once whole-cell recording has been established. Downward movement was stopped once mechanical artifact was detected on the current baseline and confirmed under visual control. The probe had a velocity ranging from 2 to $800 \mu \mathrm{m} / \mathrm{s}$ during the ramp segment of the command for forward motion, and the stimulus was applied for duration ranging from $10 \mathrm{~ms}$ to several seconds. Faster velocities tended to cause oscillation of the probe. The probe was withdrawn relatively slowly over $10 \mathrm{~ms}$, thus ensuring stability of patch-clamp recording. To assess the activation stimulus midpoint, a series of mechanical steps in $0.7 \mu \mathrm{m}$ increments was typically applied every $10-45 \mathrm{~s}$, which allowed MS currents to fully recover between each stimulus. The distance probe cell was not subtracted from the total distance traveled by the probe. Unless otherwise noted, MS currents were recorded at a holding potential of $-60 \mathrm{mV}$.

Data and statistical analysis. pClamp 8.02, pClamp 10 (Molecular Devices), and PRISM 4.0 (GraphPad Software) software suites were used to perform linear and nonlinear fitting of data. Current-stimulus $[I(X)]$ curves were fitted using the following Boltzmann function: $I / I_{\max }=1 /\left(1+\exp \left[\left(\operatorname{Stim}_{50}-\mathrm{Stim}\right) / k\right]\right)$, where $I / I_{\max }$ is the normalized current, Stim $_{50}$ is the stimulus of half-maximum channel activation, and $k$ is the steepness factor. The time courses of current decay were fitted to exponentials using the Chebyshev nonlinear leastsquares fitting procedure. Cells were classified according to the time constant of MS current relaxation and to the presence or not of a persistent MS current, which was defined as the residual current remaining after $2 \mathrm{~s}$ stimulus. Results are presented as mean \pm SEM, and $n$ represents the number of cells examined. Statistical comparisons were analyzed using Student's $t$ test or ANOVA. $p<0.05$ was considered statistically significant.

\section{Results}

Identification of four types of mechanotransducer currents in mechanosensory neurons

Mechanical stimulation of DRG neurons evoked MS inward currents in $65 \%$ of neurons tested ( $n=545$ of 835 ) (Fig. $1 A, B)$. After their initial activation, MS currents declined despite maintenance of the stimulus. By analogy with transducer properties in hair cells (Eatock et al., 1987; Crawford et al., 1989), this mechanism has been called adaptation by others (Drew et al., 2002; McCarter and Levine, 2006; Coste et al., 2007). However, because the underlying mechanism is still unknown in sensory neurons, we refer hereafter to this mechanism as current relaxation. For most mechanosensitive neurons $(n=353)$, the time course of transducer current relaxation could be best fitted by a singleexponential function. However, in $35 \%$ of recordings, relaxation exhibited multiple exponential components. Detailed kinetics analysis was made on MS currents in which the major portion of the current declined monoexponentially (Fig. 1A,B). 
A

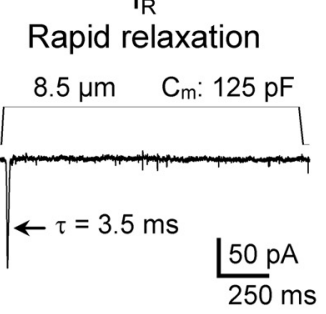

Int

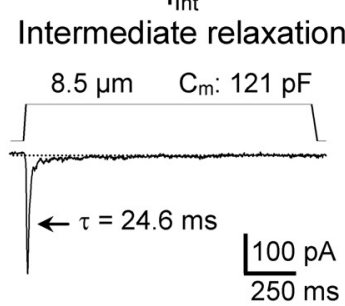

$I_{s}$ Slow relaxation

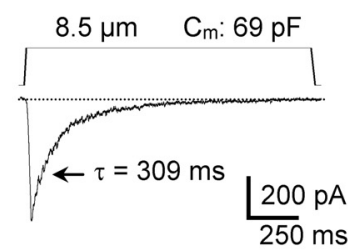

Ius

Ultra-slow relaxation

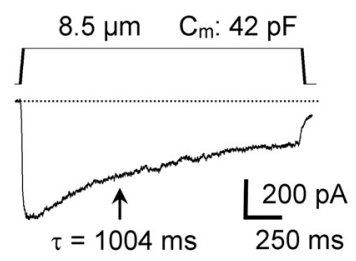

B

C

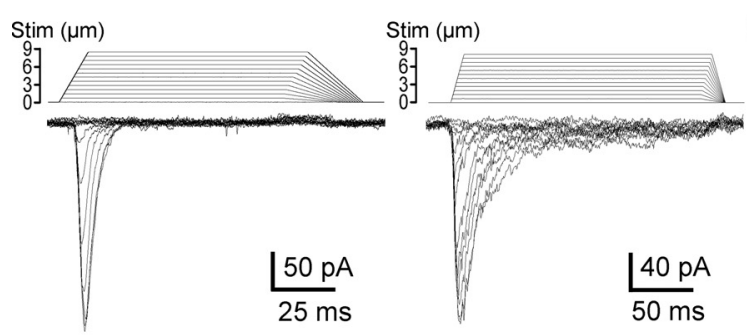

Overall DRG neuron population
D

\section{Cutaneous DRG neurons}

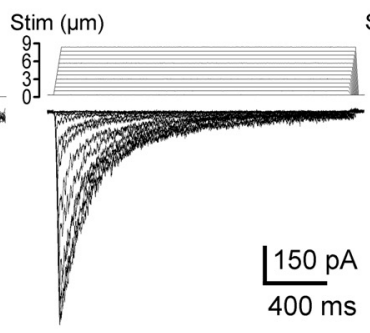

$\mathrm{C}_{\mathrm{m}}(\mathrm{pF})$

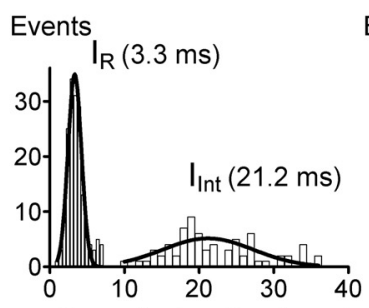

Current relaxation $(\tau, \mathrm{ms})$

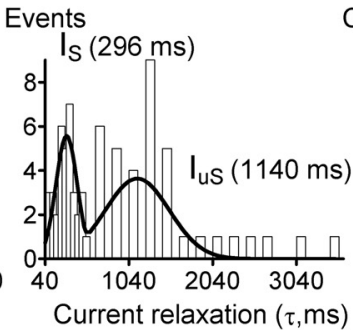

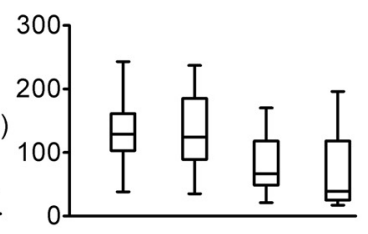

IR I Int Is lus

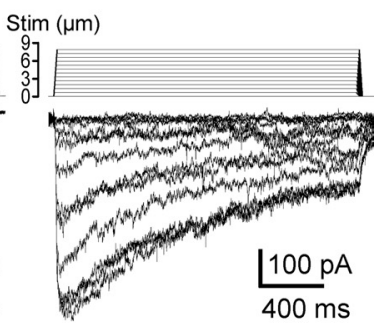

$\mathrm{E}$
Cutaneous DRG neurons

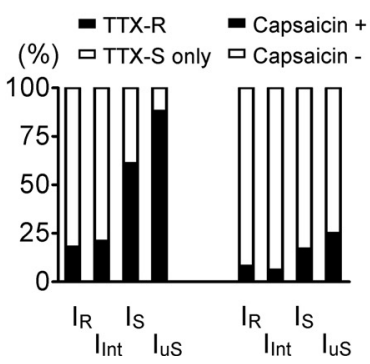

Figure 1. Properties of mechanotransducer currents in mechanoreceptors and nociceptors. $\boldsymbol{A}$, Representative traces of MS currents elicited by a standard mechanical stimulus ( $8.5 \mu \mathrm{m}$ ) in four sensory neurons $\left(C_{m}\right.$ indicated). Time constants of current relaxation are indicated in each panel. The velocity of the mechanical probe was $800 \mu \mathrm{m} / \mathrm{s}$ during the ramp segment. Holding potential, $-60 \mathrm{mV}$. B, Families of MS current traces evoked by a series of mechanical steps in $0.7 \mu \mathrm{m}$ increments for the cells shown in $A$. C, Frequency distribution of relaxation time constants. Data collected over 354 DRG neurons voltage clamped at $-60 \mathrm{mV}$ and stimulated with a standard mechanical stimulus. Gaussian fits identified four peaks of relaxation time constants. Bin width was $0.5,1,50$,

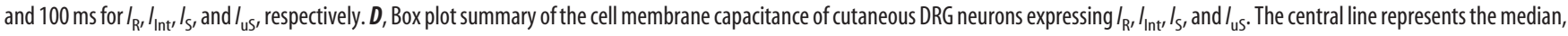
the edges of the box represent interquartiles, and the whisker lines indicate the extend of the distribution $(n=125)$. $E$, Frequency histograms indicating the proportion of $I_{R^{-}}$, $I_{\text {Int }}$, $I_{S^{-}}$, and $I_{\text {us }}$-expressing neurons that express or not TTX-R Na ${ }^{+}$currents (left) or that are sensitive or not to capsaicin (right). Data collected from 110 cutaneous DRG neurons.

Based on Gaussian distribution of relaxation time constants, four kinetically distinct MS currents could be distinguished, with rapid $\left(I_{\mathrm{R}}\right)(3.3 \pm 0.15 \mathrm{~ms}, n=184)$, intermediate $\left(I_{\text {Int }}\right)(21.2 \pm$ $0.5 \mathrm{~ms}, n=82)$, slow $\left(I_{\mathrm{S}}\right)(296 \pm 30 \mathrm{~ms}, n=38)$, and ultra-slow $\left(I_{\mathrm{uS}}\right)(1140 \pm 50 \mathrm{~ms}, n=49)$ relaxation time constants (Fig. $\left.1 C\right)$. In addition, $I_{\mathrm{uS}}$ could be discriminated against other types of currents from the presence of a "persistent" component reaching $\sim 25 \%$ of peak current after 2 -s-duration stimulus (supplemental Fig. $1 A$, available at www.jneurosci.org as supplemental material). All MS currents identified here were nonselectively carried by cations, with reversal potential ranging from -4 to $+5 \mathrm{mV}$ (supplemental Fig. $1 B, C$, available at www.jneurosci.org as supplemental material). Cutaneous DRG neurons innervating glabrous skin of the hindpaw were identified by the retrograde administration of DiI. Of 125 mechanosensory neurons innervating the skin and identified by fluorescent labeling, 39, 26, 15, and $2 \%$ exhibited $I_{\mathrm{R}}, I_{\mathrm{us}}, I_{\mathrm{Int}}$, and $I_{\mathrm{S}}$, respectively. In the remaining neurons (18\%), kinetics could not be properly extracted.

\section{Differential expression of mechanotransducer currents in} cutaneous mechanoreceptors and nociceptors

To determine whether the properties of MS currents found in cutaneous DRG neurons correlated with specific neuronal phe- notypes, we classified neurons according to cell capacitance, properties of voltage-gated sodium currents, and capsaicin sensitivity. Previous studies have shown that these parameters allow discrimination between polymodal nociceptors, LTMs and HTMs (Drew et al., 2004; Coste et al., 2007). We found a clear distinction between the phenotype distribution of MS currents. $I_{\mathrm{uS}}$ and $I_{\mathrm{S}}$ were preferentially, but not exclusively, found in neurons having a relatively small cell capacitance, whereas $I_{\mathrm{R}}$ and $I_{\text {Int }}$ were most encountered in neurons having larger cell capacitance (Fig. $1 D$ ). The majority of $I_{\mathrm{S}^{-}}$and $I_{\mathrm{us}}$-expressing neurons were found to express TTX-resistant (TTX-R) $\mathrm{Na}^{+}$ currents and, for some of them, capsaicin-induced currents (Fig. $1 E$ ). In contrast, the majority of $\mathrm{I}_{\mathrm{R}}$-and $\mathrm{I}_{\mathrm{Int}}$-expressing neurons exhibited a TTX-sensitive (TTX-S) $\mathrm{Na}^{+}$current but no TTX-R current component.

\section{Differential susceptibility of mechanotransducer currents} to desensitize

Desensitization was promoted by a $10 \mathrm{~ms}$ conditioning mechanical stimulus, graded in amplitude, and followed by a $10 \mathrm{~ms}$ test stimulus to sample channel availability (Fig. $2 A$ ). $I_{\mathrm{R}}$ and $I_{\text {Int }}$ were strongly reduced by short conditioning stimuli, indicating that the prepulse decreased the availability of MS channels. In con- 
A Rapid relaxation

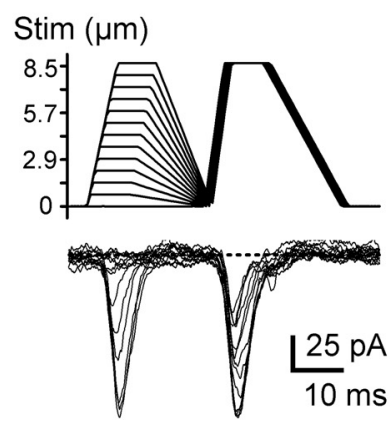

B

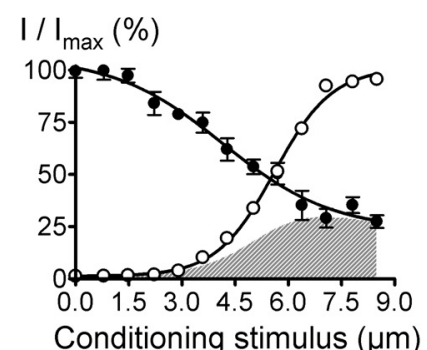

$I_{\text {Int }}$ Intermediate relaxation

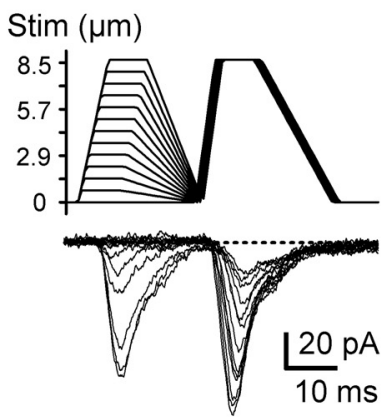

$I_{S}$ Slow relaxation

Stim $(\mu \mathrm{m})$

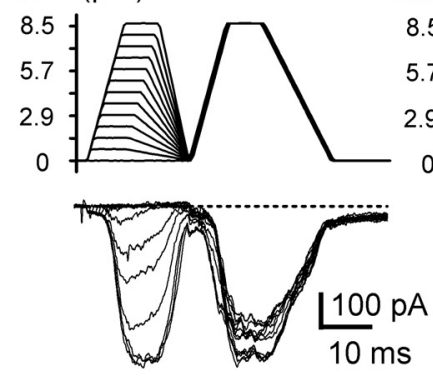

$\mathrm{l}_{\text {us }}$ Ultra-slow relaxation

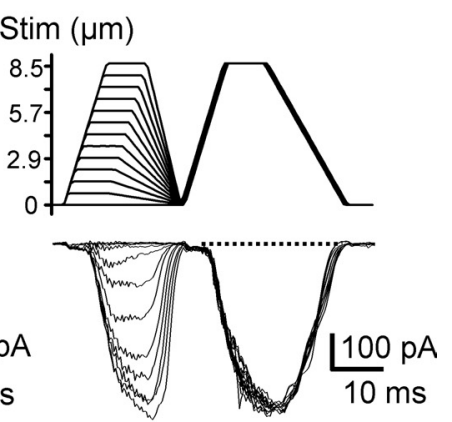

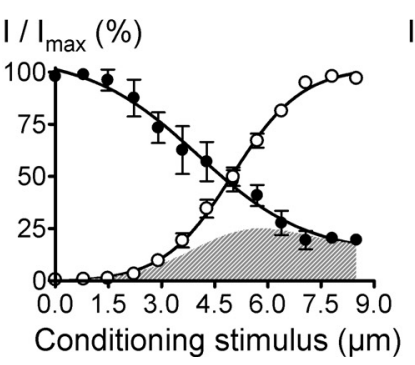

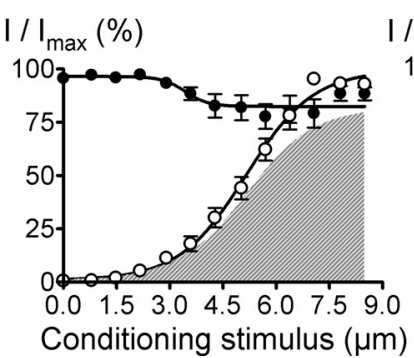

I / I $\max (\%)$

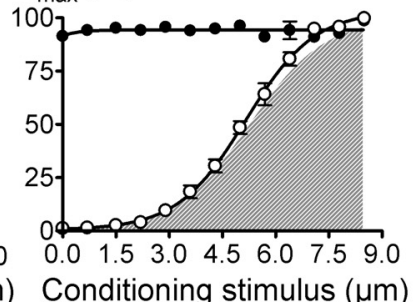

Figure 2. Differential desensitization sets functional properties of mechanotransducer currents. $\boldsymbol{A}$, Effects of conditioning mechanical stimuli on $I_{\mathrm{R}^{\prime}} I_{\text {Int }} I_{S^{\prime}}$, and $I_{\text {uS. }}$. Shown are representative current traces evoked using a series of $10 \mathrm{~ms}$ conditioning stimuli of increasing intensity $(0-8.5 \mu \mathrm{m}$ in $0.7 \mu \mathrm{m}$ increments), followed by a test stimulus to $8.5 \mu \mathrm{m}$. Sweeps were applied every $10 \mathrm{~s}$. $B$, Activation (open symbols) and availability (filled symbols) relationships determined by protocols as in $A$. Availability curves are first-order Boltzmann functions returning midpoints of $4.15 \pm 0.33$ and $4.03 \pm 0.37 \mu \mathrm{m} \mathrm{for} I_{R}$ and $I_{\text {Int }}$ respectively. Activation curves are first-order Boltzmann relations with activation stimulus midpoints $\left(\right.$ Stim ${ }_{50}$ ) of $5.6 \pm 0.04,5.00 \pm 0.08,5.2 \pm 0.11$, and $5.16 \pm$ $0.08 \mu \mathrm{m}$ for $I_{R^{\prime}} I_{\text {Int }} / I_{S^{\prime}}$ and $I_{\text {us }}$, respectively. Steepness factors were $0.81 \pm 0.03,0.98 \pm 0.08,0.95 \pm 0.1$, and $0.92 \pm 0.08 \mu \mathrm{m}$, respectively. Each data point is the mean $\pm \mathrm{SEM}(n=8-35)$. Gray areas represent window currents.

trast, $I_{\mathrm{S}}$ and $I_{\mathrm{uS}}$ were little affected by the prepulse, consistent with the modest relaxation of these currents during short mechanical stimuli. Availability curves derived from these protocols are shown in Figure $2 B$ and superimposed on activation curves determined for each MS current by applying a series of incrementing mechanical stimuli (Fig. 1B). A clear distinction between current types is the degree of overlap between the mechanical dependences of activation and availability curves. $I_{\mathrm{S}}$ and $I_{\mathrm{uS}}$ showed a much larger overlap between availability and activation curves and are therefore better suited to generating sustained currents. In contrast, $I_{\mathrm{R}}$ and $I_{\text {Int }}$ channels are not equipped to provide a steady current but are very capable of supplying transient currents. It should be noted from Figure $2 B$ that a "window" current is theoretically possible for both $I_{\mathrm{R}}$ and $I_{\text {Int. }}$. However, this window current reflected the fact that some channels recovered during the downward ramp segment of the conditioning stimulus. To gain information about repriming kinetics of $I_{\mathrm{R}}$ and $I_{\text {Int }}$, we used a double-pulse protocol, lengthening the interpulse interval gradually. Fractional recovery was well fitted with monoexponential functions with mean time constants of $7.7 \pm 1.3$ and $20.3 \pm 4 \mathrm{~ms}$ for $I_{\mathrm{R}}$ and $I_{\text {Int }}$, respectively (supplemental Fig. $1 D$, available at www.jneurosci.org as supplemental material).

\section{Desensitization of mechanotransducer currents results from} channel inactivation and adaptive shift in pressure sensing $\mathrm{I}_{R}$ and $\mathrm{I}_{\text {Int }}$

To explore the mechanisms underlying desensitization of mechanotransducer channels we determined the $I(X)$ relationship before and at various times during a maintained conditioning stimulus. For these experiments, we typically used a conditioning stimulus of intermediate amplitude near the activation stimulus midpoint. Comparison of $I_{\mathrm{R}}(X)$ curves, generated at different time points during the conditioning stimulus, shows that activation curve shifted by $\sim 1.3 \mu \mathrm{m}$ along the $x$-axis, a mechanism that we will call hereafter adaptation (Fig. $3 A-E$ ). Nevertheless, the shift in activation curve did not account for the entire effect of the conditioning stimulus. As can be seen in Figure $3 E$, the activation curve of adapted $I_{\mathrm{R}}$ channels had the same steepness as the control (non-adapted) activation curve but was reduced in amplitude relative to the control relationship. This suggested that some $I_{\mathrm{R}}$ channels had inactivated during the conditioning stimulus. When the adapted and non-adapted activation curves were scaled to adjust for changes in maximal conductance, it can be seen that both curves plateaued for high-intensity stimuli (Fig. 3E, right), indicating that inactivation predominates in this stimulus range. Contribution of adaptation and inactivation can be evidenced by comparing the percentage in reduction of $I_{\mathrm{R}}$ during the conditioning stimulus, depending on whether $I_{\mathrm{R}}$ was activated by moderate stimuli, in which both mechanisms operate, or by near-saturating stimuli, in which inactivation predominates (Fig. $3 C, D$ ). The kinetics of adaptive shift of the $I_{\mathrm{R}}(X)$ curve was investigated by sampling the activation stimulus midpoint against time after the onset of a conditioning stimulus. The data were fitted with a singleexponential function with a time constant of $4.4 \pm 1 \mathrm{~ms}$ and a mean amplitude of $1.25 \pm 0.2 \mu \mathrm{m}$ (Fig. $3 F$ ). The time course was independent of the amplitude of the conditioning stimulus (Fig. $3 G$ ). Inactivation was determined by measuring $I_{\mathrm{R}}$ evoked by saturating stimuli at various time points after the onset of the conditioning prepulse. The time course of inactivation was fitted 
by a monoexponential function with a time constant of $5.6 \pm 0.9 \mathrm{~ms}$, which was independent of the conditioning stimulus amplitude (Fig. $3 H$ ). Neither the amplitude of adaptive shift nor inactivation was proportional to the size of the conditioning stimulus (Fig. 3I). However, the position of the inactivation curve lies rightward to that of the adaptive shift, indicating that stronger mechanical stimuli are needed to promote inactivation (Fig. 3I).

$I_{S}$ and $I_{u S}$

To study $I(X)$ relationships for $I_{\mathrm{S}}$ and $I_{\mathrm{uS}}$, we delivered a series of test pulses, before and during a conditioning stimulus of moderate amplitude lasting up to $3.6 \mathrm{~s}$ (Fig. 4). Comparison of activation curves for $I_{\mathrm{S}}$ generated at different time points shows that activation curve shifted rightward along the $x$-axis by $\sim 1.44 \mu \mathrm{m}$. Activation curve had comparable steepness as the non-adapted activation curve, but its maximal amplitude was reduced by $\sim 30 \%$ (Fig. $4 A, B$ ). The adaptive shift for $I_{\mathrm{S}}$ developed with a time constant of $214 \pm$ $49 \mathrm{~ms}$ and saturated at $1.8 \pm 0.2 \mu \mathrm{m}$ (Fig. $4 C, D)$. The adaptive shift followed similar time course ( $200 \mathrm{~ms}<\tau<300 \mathrm{~ms}$ ) with conditioning stimuli ranging from 2.9 to $5.7 \mu \mathrm{m}$ (data not shown). Inactivation of $I_{\mathrm{S}}$ was determined at saturating stimuli and plotted against the amplitude of the conditioning stimulus in Figure $4 D$. The result shows that stimuli substantially above the activation stimulus midpoint are necessary to promote $I_{\mathrm{S}}$ channel inactivation. Inactivation developed with a time constant of $237 \pm 70 \mathrm{~ms}(n=5)$ (data not shown).

The same conditioning paradigm shifted $I_{\mathrm{uS}}$ activation curve by $0.75 \pm 0.2$ $\mu \mathrm{m}$ and reduced conductance by $\sim 25 \%$ within $3.4 \mathrm{~s}$ (Fig. 4E,F). Both adaptive shift and inactivation had very slow time courses of $\sim 1$ and $4.5 \mathrm{~s}$, respectively (Fig. 4G,H); these time courses were not significantly influenced by the amplitude of the conditioning stimulus (data not shown).

\section{Both channel inactivation and adaptation are regulated by voltage} A comparison of MS currents recorded at either -60 or $+60 \mathrm{mV}$ showed that current relaxation became less pronounced with membrane depolarization. Exponentials fitted to $I_{\mathrm{R}}$ traces recorded at -60 or $+60 \mathrm{mV}$ had time constants of $4 \pm 0.5$ and $27 \pm 1.9 \mathrm{~ms}$, respectively (Fig. $5 A$ ). Likewise, positive voltages also increased approximately threefold the relaxation kinetic time constants of $I_{\mathrm{uS}}$ (Fig. $5 B$ ) and $I_{\text {Int }}$ (data not shown). A plot of $\tau$ versus voltage exhibited no significant changes in $\tau$ between -60 and $0 \mathrm{mV}$ and a steep

A B

E
Rapid mechanotransducer $\left(I_{R}\right)$
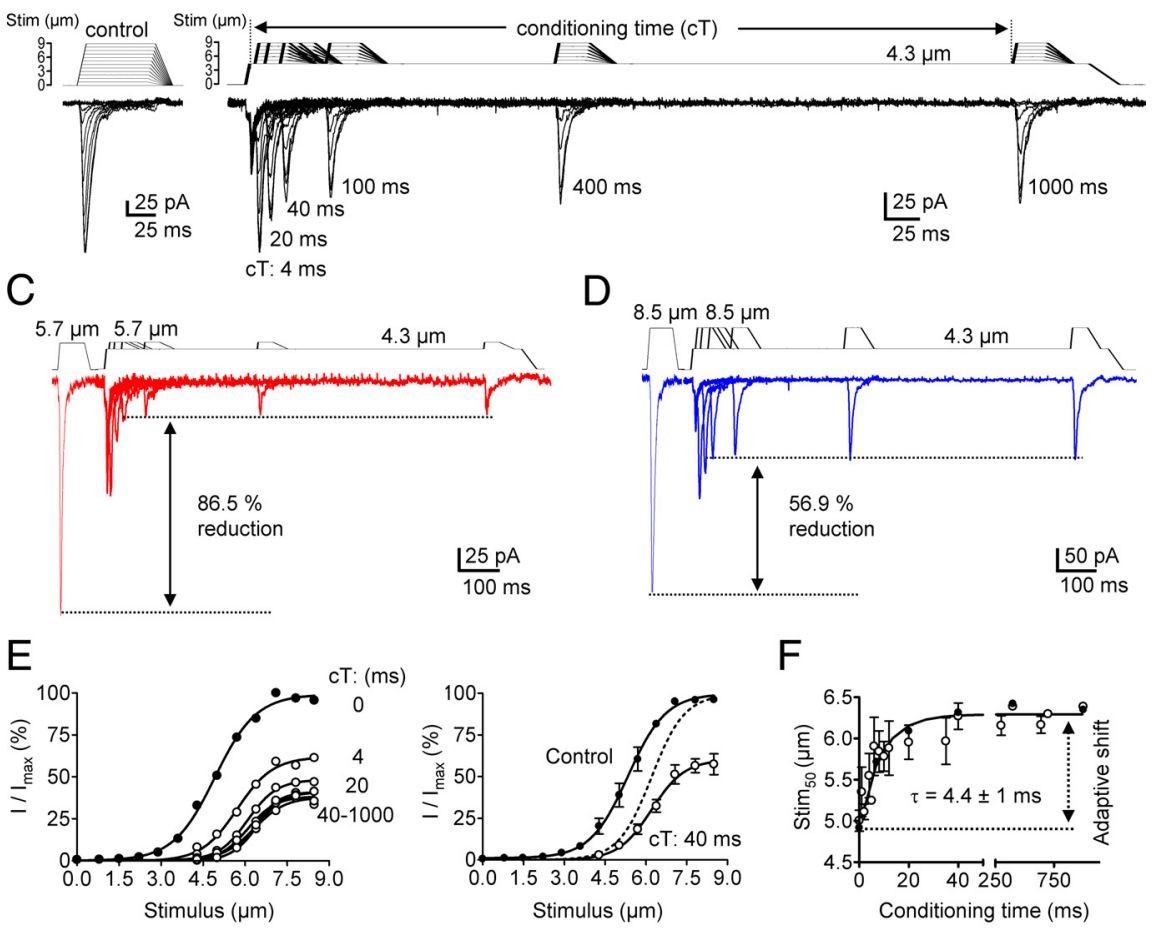

F
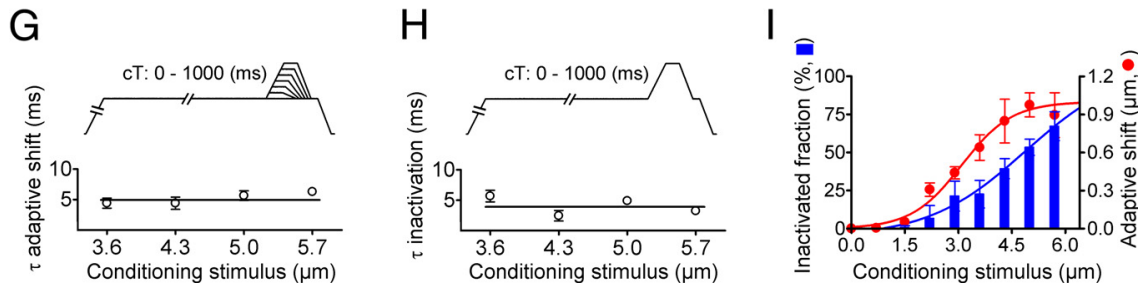

Figure 3. Alteration in pressure sensing and inactivation underlie desensitization of mechanotransducer $I_{R}$ channels. $\boldsymbol{A}$, Family of $I_{R}$ traces elicited by a series of mechanical stimuli incremented in $0.7 \mu \mathrm{m}$ steps. Sweeps were applied every $10 \mathrm{~s}$. The relaxation time constant of this current was $4.1 \mathrm{~ms}$. $\boldsymbol{B}$, Same cell as in $\boldsymbol{A}$. A conditioning stimulus ( $4.3 \mu \mathrm{m}$ ) of increasing duration $(4-1000 \mathrm{~ms})$ is now presented before a series of mechanical test steps ( $0.7 \mu \mathrm{m}$ increment) to sample channel activation and availability. The conditioning time (CT) is indicated. C, D, The $4.3 \mu \mathrm{m}$ conditioning step reduced $I_{R}$ by $\sim 86.5 \%$ when evoked by an intermediate stimulus $(5.7 \mu \mathrm{m}, \boldsymbol{C})$ and by only $56.9 \%$ when evoked by a saturating stimulus $(8.5 \mu \mathrm{m}, \boldsymbol{D}) . \boldsymbol{E}$, Left, $I_{\mathrm{R}}(X)$ relationships determined before $(O)$ and at different times $(\bigcirc ; 4-1000 \mathrm{~ms})$ after the onset of the conditioning stimulus. First-order Boltzmann relations yielded a Stim $_{50}$ of $4.92 \mu \mathrm{m}$ in control conditions and of $5.72,6.09,6.32,6.11,6.2$, and $6.21 \mu \mathrm{m}$ at conditioning times of 4,20,40, 100,400 , and $1000 \mathrm{~ms}$, respectively. Right, First-order Boltzmann relations obtained from eight cells determined before $(\boldsymbol{O})$ and $40 \mathrm{~ms}$ after $(O)$ the onset of a conditioning stimulus of $4.3 \mu \mathrm{m}$. The dashed line represents the Boltzmann curve through the adapted $I_{R}(X)$ relation normalized to the control activation curve. Stim ${ }_{50}$ and slope factors were $5.3 \pm 0.03 \mu \mathrm{m}$ and $0.70 \pm 0.04$ for the control activation curve and $6.3 \pm 0.06 \mu \mathrm{m}$ and $0.72 \pm 0.05$ for the adapted activation curve. $\boldsymbol{F}$, Time course of the shift in the activation pressure midpoint $\left(\mathrm{Stim}_{50}\right)$ as a function of conditioning time. A single-exponential function with a $\tau$ of $4.4 \pm 1$ ms $(n=12)$ provided the best fit to the data. The filled symbols are from the neuron illustrated in $\boldsymbol{E}$. Note that $\Delta$ Stim ${ }_{50}$ gives the amplitude of the adaptive shift induced by a conditioning stimulus of $4.3 \mu \mathrm{m} . \mathbf{G}, \boldsymbol{H}$, Averaged time constants of the adaptive shift $(\boldsymbol{G})$ and inactivation $(\boldsymbol{H})$ plotted against the amplitude of the conditioning stimulus. Each data point is the mean \pm SEM of $6-10$ cells. Note that kinetics remained constant regardless of the amplitude of the stimulus. I, Amplitude of the adaptive shift (red circles) and inactivated fraction (blue bars) of $I_{R}$ channels plotted against the amplitude of the conditioning stimulus. The adaptive shift reflects the shift of the midpoint of each adapted $I_{R}(X)$ curves relative to the midpoint of the control (non-adapted) curve. The Boltzmann curves through the points had a midpoint value of $3.05 \pm 0.46 \mu \mathrm{m}$ for the adaptive shift and a midpoint value of $4.83 \pm 0.22 \mu \mathrm{m}$ for inactivation $(n=20-25)$.

slowing above $0 \mathrm{mV}$ for both $I_{\mathrm{R}}$ and $I_{\mathrm{uS}}$ (Fig. $5 C, D$ ). The break point in the $\tau(V)$ dependence was close to the reversal potential of MS currents. To evaluate whether the direction of the current flow influenced the $\tau(V)$ relationship, we used an asymmetrical chemical gradient setting $E_{\mathrm{rev}}$ at $-60 \mathrm{mV}$ (supplemental Fig. 2, available at www.jneurosci.org as supplemental material). The break point of the $\tau / V$ relationship remained identical, no matter the direction of the current flow. 
A

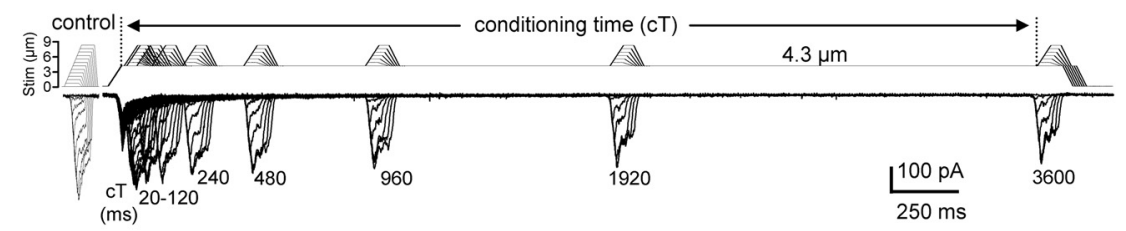

B

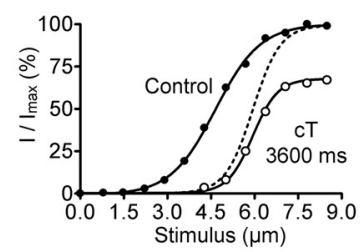

C
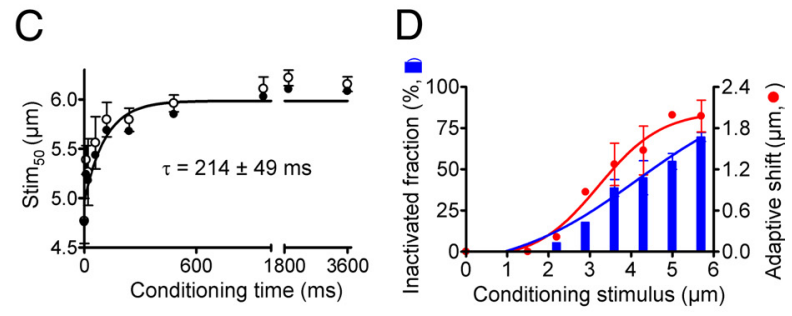

$\mathrm{E}$

Ultra-slow mechanotransducer $\left(\mathrm{I}_{\mathrm{uS}}\right)$

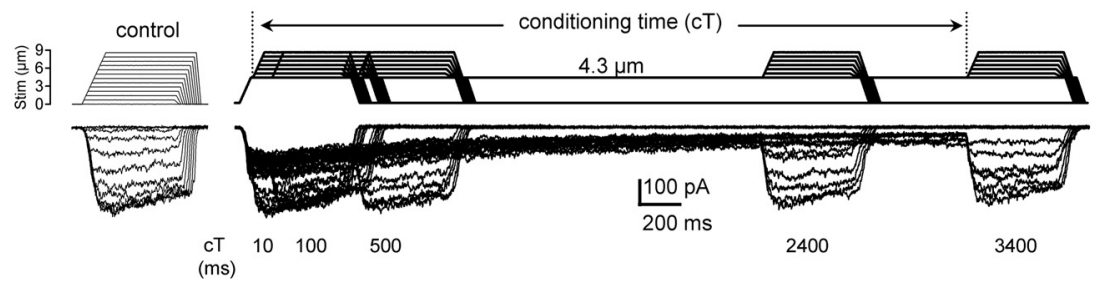

$\mathrm{F}$



$\mathrm{G}$
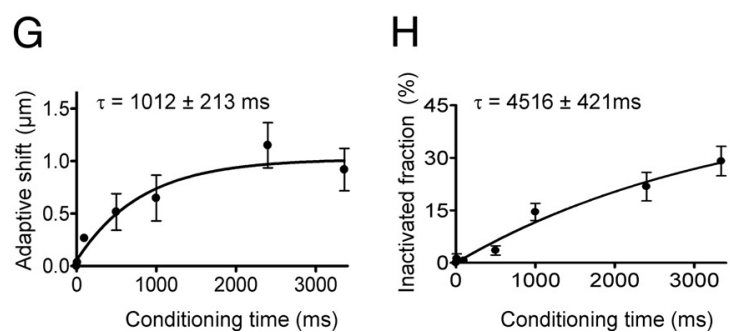

Figure 4. Kinetics of adaptation and inactivation of slow and ultra-slow mechanotransducer currents. $A$, I $/$ traces elicited by a series of mechanical steps before and during a conditioning stimulus $(4.3 \mu \mathrm{m})$ of increasing duration $(20-3600 \mathrm{~ms})$. The relaxation time constant of this current is $205 \mathrm{~ms}$. Steps were applied every 45 s and incremented by $0.7 \mu \mathrm{m}$ steps. $\boldsymbol{B}, I_{s}(X)$ relationships determined before $(O)$ and $3600 \mathrm{~ms}$ after $(\bigcirc)$ the onset of the conditioning stimulus. First-order Boltzmann relations yielded a Stim $_{50}$ of $4.7 \mu \mathrm{m}$ in control and of $6.1 \mu \mathrm{m}$ at conditioning time of $3600 \mathrm{~ms}$. Steepness factors were 0.7 and 0.8 , respectively. The dashed line represents the Boltzmann curve through the adapted $I_{s}(X)$ relation normalized to the control activation curve. $C$, Shift in Stim ${ }_{50}$ as a function of conditioning time. Monoexponential fit returned a $\tau$ of $214 \pm 49 \mathrm{~ms}(n=6)$. Filled symbols are from the neuron illustrated in $\boldsymbol{A}$ and $\boldsymbol{B}$. $\boldsymbol{D}$, Amplitude of the adaptive shift (red circles) and inactivated fraction (blue bars) of $I_{5}$ channels plotted against the amplitude of the conditioning stimulus. Midpoint value for the adaptive shift was of $3.26 \pm 0.2 \mu \mathrm{m}(n=5)$ and $4.43 \pm 0.27 \mu \mathrm{m}$ for the inactivation curve $(n=8)$. $\boldsymbol{E}, I_{\mathrm{us}}$ traces elicited by a series of mechanical steps before (control) and during a conditioning stimulus $(4.3 \mu \mathrm{m})$ of increasing duration $(10-3400 \mathrm{~ms})$. The relaxation time constant of this current was $1207 \mathrm{~ms}$. Steps were applied every $45 \mathrm{~s}$ and incremented by $0.7 \mu \mathrm{m} . \boldsymbol{F}_{,} I_{\text {us }}(X)$ relationships determined before $(\boldsymbol{O})$ and $3400 \mathrm{~ms}$ after $(\bigcirc)$ the onset of the conditioning stimulus. First-order Boltzmann relations yielded a $S_{\text {tim }}$ of 4.2 and $5.5 \mu \mathrm{m}$ and steepness factors of 0.95 and 0.9 , respectively. The dashed line represents the Boltzmann curve through the adapted $I_{u s}(X)$ curve normalized to the control activation curve. $\boldsymbol{G}, \boldsymbol{H}$, Adaptive shift $(\boldsymbol{G})$ and fractional inactivation $(\boldsymbol{H})$ plotted against conditioning time. Exponential fits returned $\tau$ of $1012 \pm 213$ and $4516 \pm 421 \mathrm{~ms}$, respectively. Averaged data from seven neurons.

Whether voltage affects kinetics of adaptation and inactivation was examined in Figure $5 E$. The rate of adaptive shift was estimated both at -60 and $+60 \mathrm{mV}$ by sampling the position of the $I_{\mathrm{R}}(X)$ relationship during a standard conditioning stimulus. The time constant of adaptive shift was increased threefold, from $4 \pm 0.6$ to $12 \pm 2 \mathrm{~ms}$ when switching from -60 to $+60 \mathrm{mV}$ (Fig. $5 E)$. Fast inactivation followed the same pattern with a threefold increase in its time constant (from $6.6 \pm 0.3$ to $18.4 \pm 1.3 \mathrm{~ms}$ ) (Fig. 5E). Positive voltages also slowed down relaxation kinetics of $I_{\text {Int }}, I_{\mathrm{S}}$, and $I_{\mathrm{uS}}$ by acting on the time course of both adaptation and inactivation (data not shown).

We tested whether the voltage dependence of MS current relaxation was sensitive to variation in extracellular as well as intracellular $\left[\mathrm{Ca}^{2+}\right]$. Detailed analysis was made on $I_{\mathrm{R}}$ using intracellular solutions containing various concentrations of the $\mathrm{Ca}^{2+}$ buffers, BAPTA or EGTA, and free $\left[\mathrm{Ca}^{2+}\right]_{\mathrm{i}}$ set at either 1 or $112 \mathrm{nM}(\mathrm{Ta}-$ ble 1 , Solutions $1-5)$. Chelating $\left[\mathrm{Ca}^{2+}\right]_{\mathrm{i}}$ or nominally free $\left[\mathrm{Ca}^{2+}\right]_{\mathrm{o}}$ had no significant effects on the relaxation time constants of $I_{\mathrm{R}}$ at either -60 or $+60 \mathrm{mV}$ (Fig. $5 F$ ) or on the relaxation of the three other types of MS currents (supplemental Fig. 3, available at www.jneurosci.org as supplemental material) (data not shown).

\section{Long-duration mechanical stimulus promotes mechanical refractory period of $I_{\mathrm{R}}$ channels}

We noticed that large mechanical stimuli of long duration caused $I_{\mathrm{R}}$ channels to enter a nonconducting state from which recovery could take several hundreds of milliseconds. An example of such an experiment is shown in Figure 6. $I_{\mathrm{R}}$ was first evoked by a $10 \mathrm{~ms}$ conditioning stimulus of $7.8 \mu \mathrm{m}$, followed by a $10 \mathrm{~ms}$ test stimulus to sample channel availability. This procedure reduced $I_{\mathrm{R}}$ by $\sim 50 \%$ as a result of fast inactivation developing during the short conditioning stimulus (see above). The conditioning stimulus was then lengthened from 50 to $1000 \mathrm{~ms}$ (Fig. 6A). After $200 \mathrm{~ms}$ conditioning step, $I_{\mathrm{R}}$ was reduced by $63 \%$. The reduction further increased to $83 \%$ with $600 \mathrm{~ms}$ conditioning stimulus and then plateaued. Because the adaptive shift saturated for large conditioning mechanical stimuli (Fig. 3I), we hypothesized that reduction in $I_{\mathrm{R}}$ resulted from entry of $I_{\mathrm{R}}$ channels into a slow inactivated state. However, to rule out a contribution of adaptation, we converted $I_{\mathrm{R}}$ traces obtained during the forward ramp segment of the mechanical stimulus into $I(X)$ relationship (Fig. $6 B$ ). This revealed that the shift in $I_{\mathrm{R}}(X)$ relation determined after a $600 \mathrm{~ms}$ conditioning stimulus was identical to the shift obtained after a $20 \mathrm{~ms}$ conditioning stimulus (Fig. $6 B, C$ ), indicating that long-duration stimuli did not promote further adaptation of $I_{\mathrm{R}}$ channels. Kinetics of $I_{\mathrm{R}}$ channel entry into slow inactivated states was fitted with a monoexponential function, yielding a mean time constant of $347 \pm 40 \mathrm{~ms}$ (Fig. 6C). In contrast to recovery from fast inactivation, which is monoexponential (supplemental Fig. $1 D$, available at www.jneurosci.org as supplemental material), recovery of $I_{\mathrm{R}}$ channels from slow inactivation was best fitted by the sum of two exponential functions of approximately 
equal amplitude with time constants of $100-230$ and 2000-2600 ms (Fig. 6D,E).

\section{Effect of mechanotransducer} desensitization on firing responses To examine the role of mechanotransducer channel desensitization on the excitability of sensory neurons, recordings were made using a $\mathrm{KCl}$-based pipette solution. Identification of the current was first monitored in voltage-clamp mode, and firing behavior was then studied in the current-clamp mode. Figure 7 shows representative responses to mechanical stimulation in four cutaneous DRG neurons expressing $I_{\mathrm{R}}, I_{\text {Int }}, I_{\mathrm{S}}$, and $I_{\mathrm{uS}}$. At subthreshold mechanical intensities, membrane potential changes reflected passive membrane behavior. Above a threshold pressure intensity, neurons expressing $I_{\mathrm{R}}$ or $I_{\text {Int }}$ fired a single AP during the dynamic phase of the stimulus but remained silent during its static phase (Fig. $7 A, B)$. This phasic discharge resulted from the rapid relaxation of mechanotransducer currents because the neurons fired regularly in response to depolarizing current injection (Fig. 7A, B, right panels). In contrast, DRG neurons expressing $I_{\mathrm{S}}$ or $I_{\mathrm{uS}}$ responded to mechanical stimulus by more sustained depolarization and firing (Fig. 7C,D). Different degrees of firing adaptation were seen between $I_{\mathrm{S}^{-}}$or $I_{\mathrm{uS}}$-expressing neurons. We quantified firing responses by computing the number of APs as a function of mechanical intensity. The number of APs increased proportionally with stimulus strength in $I_{\mathrm{S}^{-}}$and $I_{\mathrm{uS}} \mathrm{S}^{-}$but not in $I_{\mathrm{R}^{-}}$and $I_{\mathrm{Int}^{-}}{ }^{-}$ expressing neurons, which responded in an all-or-none manner (Fig. 7E).

The impact of desensitization of $I_{\mathrm{R}}$ and $I_{\mathrm{uS}}$ on firing following was also examined using pulse train of short-duration mechanical stimuli. Our data indicate that, although mechanical stimulation evoked APs and drove $I_{\mathrm{R}}$-expressing neurons at low frequencies $(1-16 \mathrm{~Hz})$, neurons were unable to follow mechanical pulse trains above $16 \mathrm{~Hz}$ (Fig. $7 F$ ). This fatigue phenomenon occurred because of incomplete recovery of $I_{\mathrm{R}}$ channels with high stimulus frequencies and was not subsequent to $\mathrm{Na}^{+}$ channel inactivation because neurons kept their ability to fire in response to current injection at frequency $>21 \mathrm{~Hz}$ (Fig. $7 F$, left). Action potentials faithfully followed high-frequency mechanical stimulation in $I_{\mathrm{us}}$-expressing neurons (Fig. 7G).

The electrophysiological impact of mechanical refractory period caused by slow inactivation of $I_{\mathrm{R}}$ channels was also investigated using paired-pulse mechanical stimulation of longduration stimuli (supplemental Fig. 4A, available at www. jneurosci.org as supplemental material). This paradigm caused $I_{\mathrm{R}}$-expressing neurons to develop a mechanical refractory period that could last several hundreds of milliseconds. Because this effect occurred only after long but not short conditioning stimuli, it is likely to result from entry of $I_{\mathrm{R}}$ channels into slow inactivated states. Consistently, no failure in responses was
B
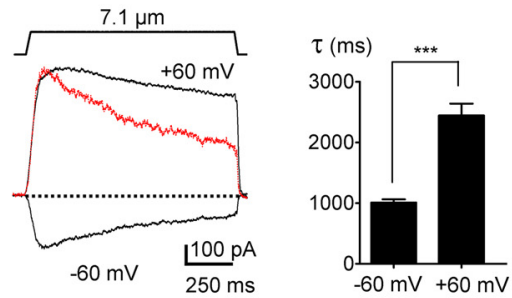

D
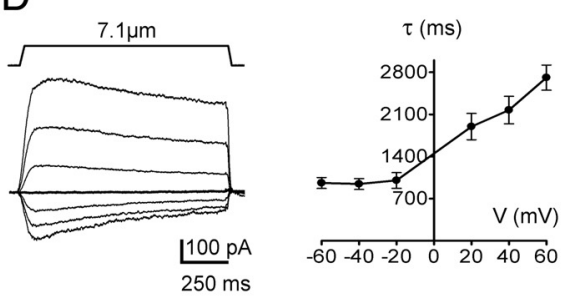

G $\square$ Adaptive shift $\square$ Inactivation

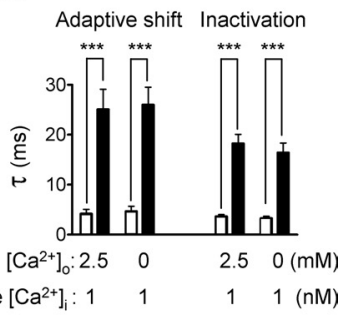

$\left[\mathrm{Ca}^{2+}\right]_{\mathrm{i}}: \begin{array}{llllllllll}1 & 112 & 1 & 112 & 1(\mathrm{nM}) & \text { Free }\left[\mathrm{Ca}^{2+}\right]_{\mathrm{i}}: 1 & 1 & 1 & 1(\mathrm{nM})\end{array}$

Solutions $\begin{array}{llllll}1 & 2 & 4 & 5 & 1\end{array}$

Figure 5. Positive potentials oppose desensitization of mechanotransducer channels. $\boldsymbol{A}, \boldsymbol{B}, \mathrm{Left}, I_{\mathrm{R}}(\boldsymbol{A})$ and $I_{\mathrm{uS}}(\boldsymbol{B})$ evoked by a bars) or $+60 \mathrm{mV}$ (black bars) with different concentrations of extracellular calcium (as listed). Data recorded with solution 1.n $n=7-10$

seen when APs were evoked by injecting depolarizing currents (data not shown), which argued against a contribution of $\mathrm{Na}^{+}$ channel inactivation in this refractory period. Long-duration stimulation had little impact on the ability of $I_{\mathrm{us}}$-expressing neurons to follow stimulation (supplemental Fig. $4 B$, available at www.jneurosci.org as supplemental material).

\section{Mechanotransducer desensitization kinetics serves to encode} the dynamic parameters of the mechanical stimulus

To investigate whether mechanotransducer current amplitude depends on the rate of stimulus application, cutaneous DRG neurons were subjected to stimuli having linear velocities ranging from 10 to $800 \mu \mathrm{m} / \mathrm{s}$. A plot of current amplitude as a function of the velocity of the stimulus revealed that there is a strong correlation between the amplitudes of $I_{\mathrm{R}}$ and $I_{\text {Int }}$ and the onset speed of the stimulus (Fig. 8A-C). In effect, a threefold reduction in linear velocity fully occluded $I_{\mathrm{R}}$, suggesting that two competing processes, activation and desensitization, were superimposed. $I_{\text {Int }}$, however, showed a lesser sensitivity to changes in the rate of stimulus onset compared with $I_{\mathrm{R}}$ (regression slope of 0.09 vs 0.17 $\mathrm{s} / \mu \mathrm{m}$, respectively). In contrast, $I_{\mathrm{uS}}$ showed a weak dependency on the rate of stimulus onset, an 80 -fold reduction in velocity reducing $I_{\mathrm{uS}}$ amplitude by $\sim 50 \%$ (Fig. $8 D, E$ ). Electrophysiolog- 
A

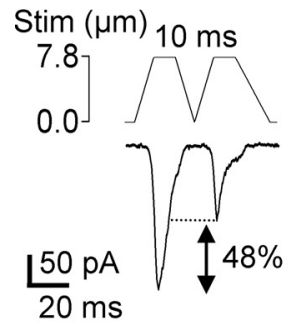

B
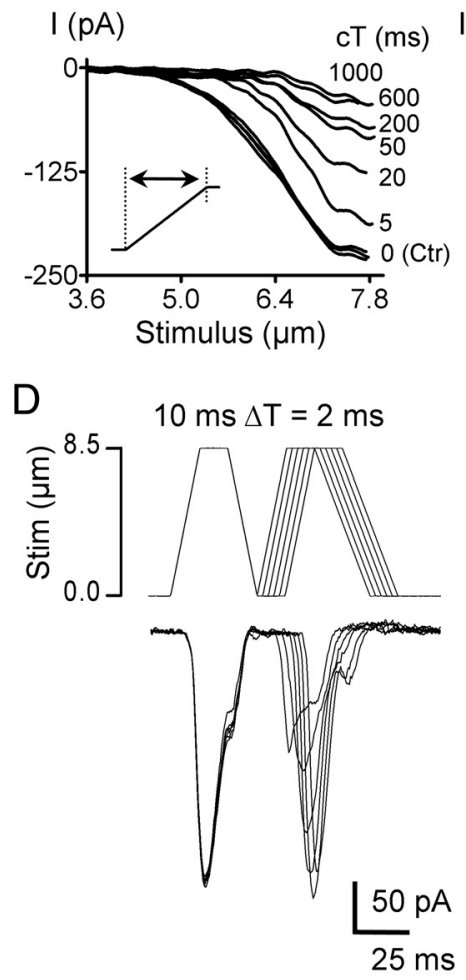

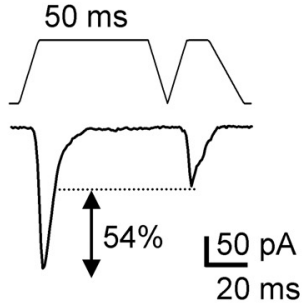

$20 \mathrm{~ms}$

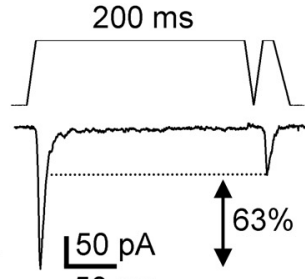

$50 \mathrm{~ms}$

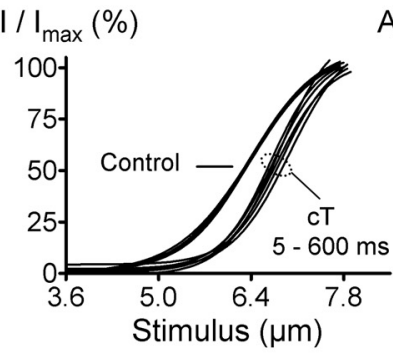

$200 \mathrm{~ms}$

$\Delta \mathrm{T}=200 \mathrm{~ms}$
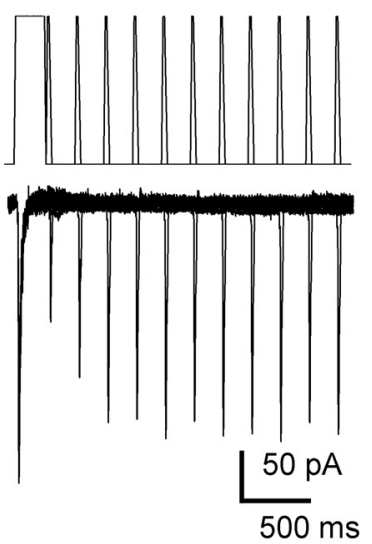

C

Adaptive shift $(\mu \mathrm{m})$

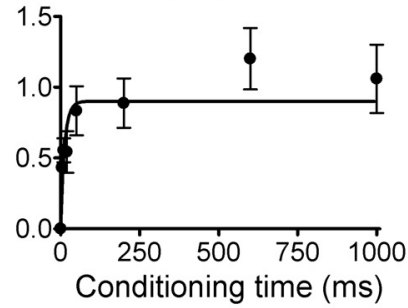

$600 \mathrm{~ms}$

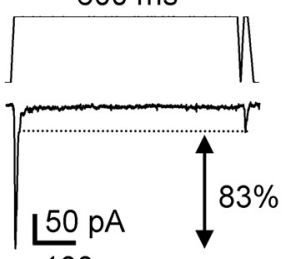

$100 \mathrm{~ms}$

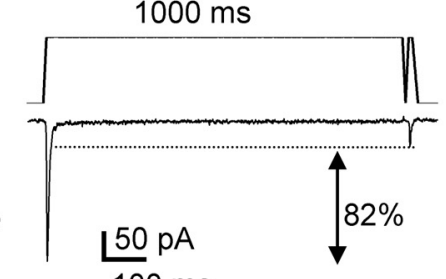

$100 \mathrm{~ms}$
E

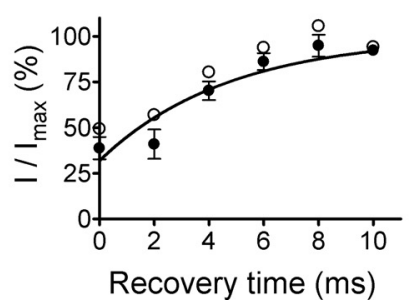

cT: $200 \mathrm{~ms}$

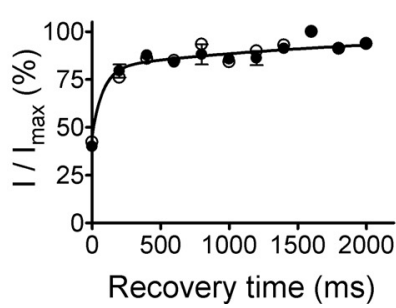

$600 \mathrm{~ms} \quad \Delta \mathrm{T}=200 \mathrm{~ms}$
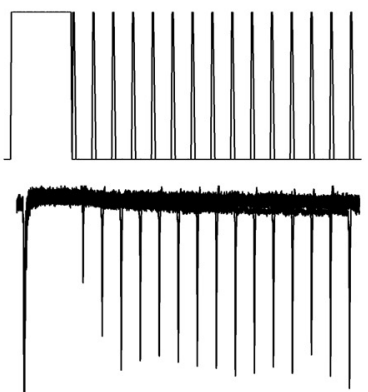

$\frac{50 \mathrm{pA}}{1000 \mathrm{~ms}}$

cT: $600 \mathrm{~ms}$

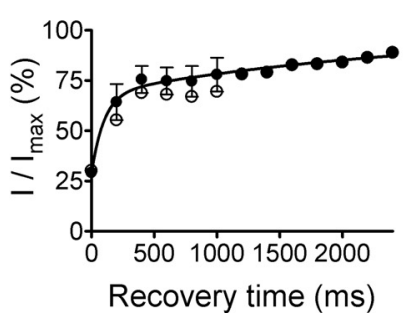

Inactivated fraction (\%)

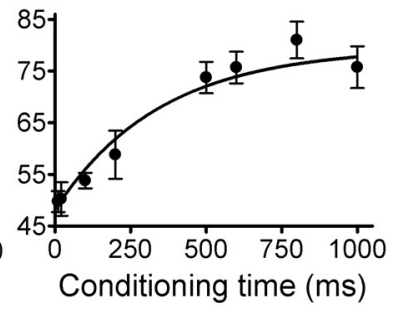

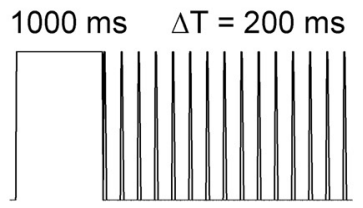

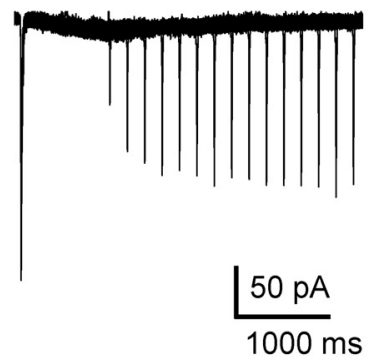

cT: $1000 \mathrm{~ms}$

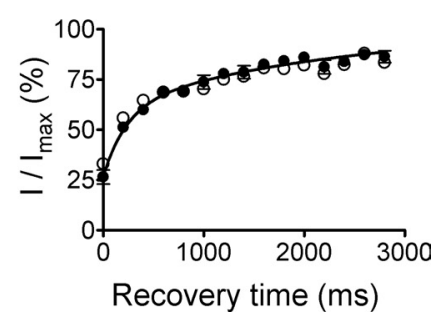

Figure 6. Refractory period of $I_{R}$ channels caused by long-duration mechanical stimuli. $\boldsymbol{A}$, Effect of lengthening the duration of the conditioning mechanical stimulus (10-1000 ms) in double-pulse protocol. Reduction in $I_{R}$ amplitude is indicated in each panel. $\boldsymbol{B}$, Data from the cell shown in $\boldsymbol{A}$. Left, Superimposition of $I_{R}$ traces recorded during the forward ramp segment of the conditioning stimulus (control, $\mathrm{Ctr}$ ) and during the forward ramp segment of the test stimulus. The duration of the conditioning stimulus is indicated. Right, Normalized Boltzmann curves derived from $I_{R}(X)$ relationships. $C$, The adaptive shift and inactivated fraction were plotted against conditioning time. The data points were fitted to one-phase exponential functions, giving time constants of $5.2 \pm 2$ and $347 \pm 40 \mathrm{~ms}$, respectively $(n=4-8)$. $D$, Recovery from inactivation. A conditioning stimulus of $8.5 \mu \mathrm{m}$ is followed by varying durations of the recovery period before a test pulse of $8.5 \mu \mathrm{m}$ to assay availability of $I_{R}$ channels. Sweeps were applied every $30 \mathrm{~s}$, which allowed full recovery of the current. $E$, Fraction of recovered $I_{R}$ plotted against the recovery period duration. Open symbols are data from $\boldsymbol{D}$, and filled symbols are averaged data from four to eight cells. Solid lines are monoexponential or biexponential fits giving mean recovery time constants of $6.6 \pm 0.8 \mathrm{~ms}(\mathrm{cT}=10 \mathrm{~ms}), 80 \pm 28$ and $2015 \pm 200 \mathrm{~ms}(\mathrm{cT}=200 \mathrm{~ms}), 100 \pm 18$ and $2615 \pm 209 \mathrm{~ms}(\mathrm{cT}=600 \mathrm{~ms})$, and $230 \pm 35$ and $2232 \pm 43 \mathrm{~ms}(\mathrm{cT}=1000 \mathrm{~ms})$.

ical impact of varying stimulus velocity was investigated in current-clamp mode in $I_{\mathrm{R}^{-}}, I_{\mathrm{Int}^{-}}$, and $I_{\mathrm{uS}}$-expressing neurons (Fig. $8 F-H)$. For all $I_{\mathrm{R}}$ and $I_{\text {Int }}$ cells tested $(n=12)$, firing ceased as the velocity of the mechanical stimulus decreased, indicating that these currents are suited to encode the dynamic part of the stim- ulus but not its static phase. In contrast, $I_{\mathrm{uS}}$-expressing cells still fired continuously when linear velocity of the mechanical stimulus was dropped from 420 to $2 \mu \mathrm{m} / \mathrm{s}$ (Fig. $8 H$ ). Thus, $I_{\mathrm{R}}$ can act as velocity detector, whereas $I_{\mathrm{uS}}$ can encode duration of the stimulus and carry tonic signals. 
A

$\mathrm{I}_{\mathrm{R}}$-expressing neuron
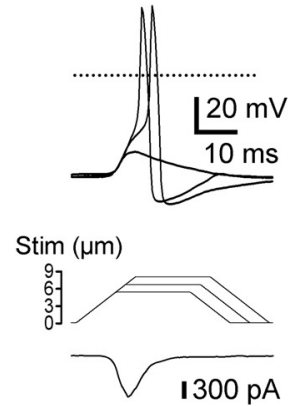

C $I_{S}$-expressing neuron
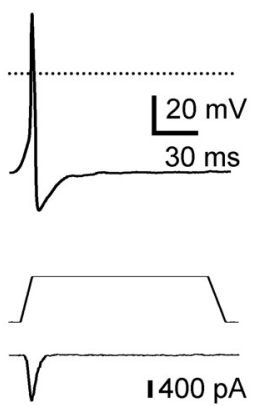

B

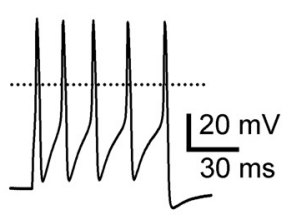

$I_{\text {Int }}$-expressing neuron

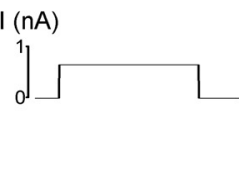

Stim (
9
6
3
0

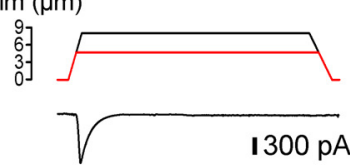

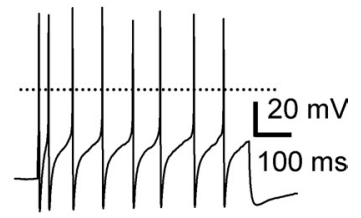

I (nA)
D

$\mathrm{I}_{\mathrm{uS}}$-expressing neuron

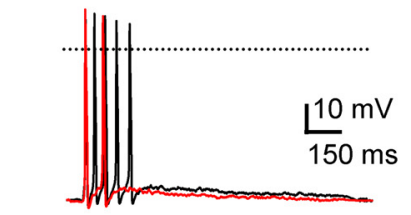

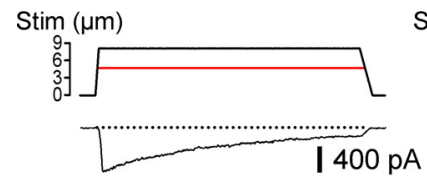

F $I_{R}$-expressing neuron

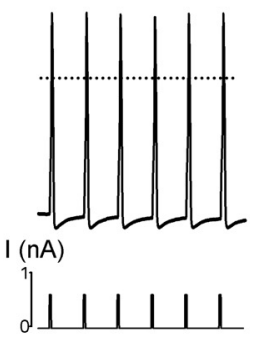

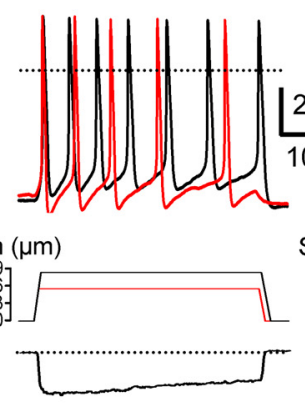

Stim
9
6
3
0
0

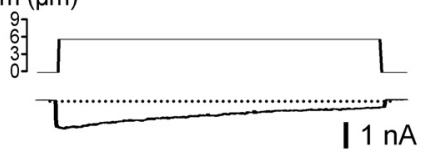

I $1 \mathrm{nA}$

\section{E}

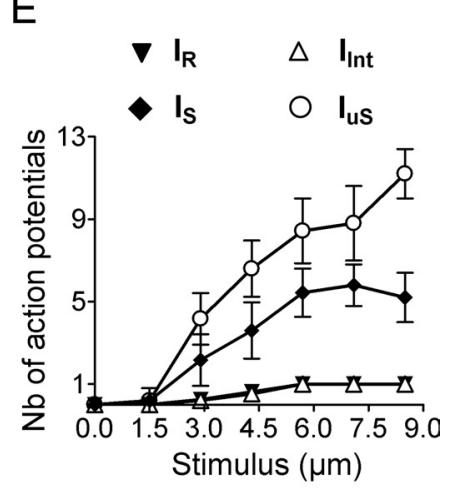

G

$\mathrm{I}_{\mathrm{uS}}-$ expressing neuron
$12 \mathrm{~Hz}$

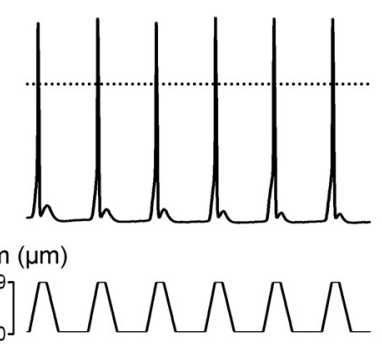

$16 \mathrm{~Hz}$

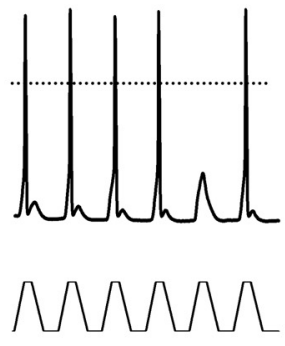

$21 \mathrm{~Hz}$

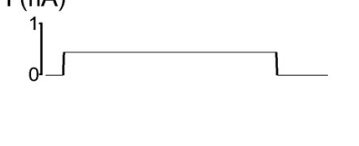

Figure 7. Desensitization of mechanotransducer currents shapes firing adaptation in sensory neurons. $\boldsymbol{A}-\boldsymbol{D}$, Current-clamp responses evoked by mechanical stimuli in DRG neurons expressing $I_{R}(\boldsymbol{A}), I_{\text {Int }}(\boldsymbol{B}), I_{S}(\boldsymbol{C})$, or $I_{\mathrm{uS}}(\boldsymbol{D})$. The dotted line indicates $0 \mathrm{mV}$ level. Note that, although $I_{\mathrm{R}}$ - and $I_{\text {Int }}$-expressing neurons fire phasically in response to mechanical stimulus, they generate a train of action potentials in response to depolarizing current pulses. $I_{\mathrm{R}^{-}}$and $I_{\text {Int }}$-expressing neurons were nociceptive cells (presence of TTX-R Na ${ }^{+}$currents). $\boldsymbol{E}$, Number of action potentials per 500 ms plotted against the intensity of the mechanical stimulus in cells expressing $I_{\mathrm{R}}(\nabla, n=8), I_{\text {Int }}(\triangle, n=6), I_{\mathrm{S}}(\bullet, n=8)$, and $I_{\text {uS }}(\bigcirc, n=7)$. $\boldsymbol{F}$, Failure of evoked responses to follow high-frequency mechanical stimulation in an $I_{R}$-expressing neuron. Responses were evoked by a $10 \mathrm{~ms}$ mechanical stimulus applied at frequencies ranging from 12 to $21 \mathrm{~Hz}$. Note no failures were seen in response to $3 \mathrm{~ms}$ depolarizing current pulses applied at $21 \mathrm{~Hz}$ (left). $\mathbf{G}$, Absence of failure of evoked responses to follow high-frequency mechanical stimulation in an Is $_{\text {-expressing nociceptive neuron. }}$

\section{Discussion}

Identification of four types of mechanotransducer currents in sensory neurons

Based on kinetics analysis, we identified four types of cationic mechanotransducer currents in rat DRG neurons. Previous studies have classified MS currents as rapidly, intermediately, or slowly adapting currents (Drew et al., 2002, 2004). The kinetics of $I_{\mathrm{R}}$ found here is very similar to that of RA current (Drew et al., 2004; Hu and Lewin, 2006). $I_{\mathrm{S}}$ and $I_{\mathrm{uS}}$ are likely to correspond to previously described IA and SA currents, although detailed kinetics analysis of these currents is lacking. $I_{\mathrm{Int}}$ is identified here for the first time. Analysis made in $>350$ cells indicates that $I_{\mathrm{R}}$ and $I_{\mathrm{uS}}$ are the most commonly encountered MS currents in sensory neurons, regardless of their target of innervation. Both $I_{\mathrm{R}}$ and $I_{\mathrm{uS}}$ were also predominantly found in DRG neurons innervating the glabrous skin of the hindpaw. $I_{\mathrm{S}}$ was rarely encountered in cutaneous DRG neurons (2\%) compared with the overall population $(\sim 10 \%)$, indicating that these neurons might have different targets of innervation. Interestingly, most mechanosensitive DRG neurons expressing $I_{\mathrm{S}}$ or $I_{\mathrm{uS}}$ exhibited TTX-R Na ${ }^{+}$currents, indicating that these cells are nociceptive; only a small fraction of them showed polymodal properties by responding to capsaicin. In contrast, $I_{\mathrm{R}}$ was preferentially found in DRG neurons with relatively large diameter and expressing predominantly TTX-S $\mathrm{Na}^{+}$currents, suggesting that they belong to a class of nonnociceptive mechanoreceptors. Therefore, our data indicate that 
A

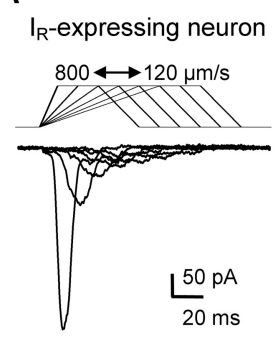

B $\mathrm{I}_{\text {Int }}$-expressing neuron

D

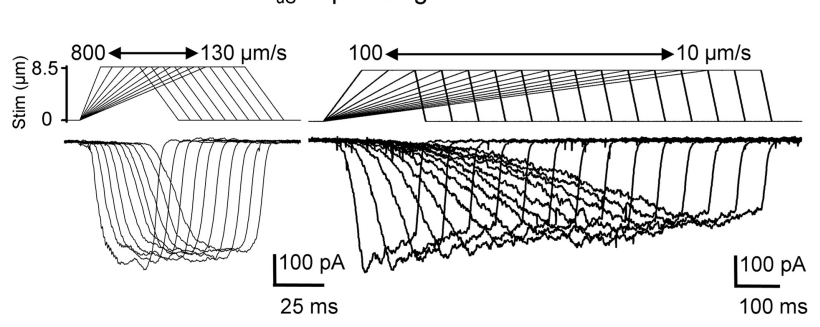

$\mathrm{I}_{\mathrm{uS}}$-expressing neuron

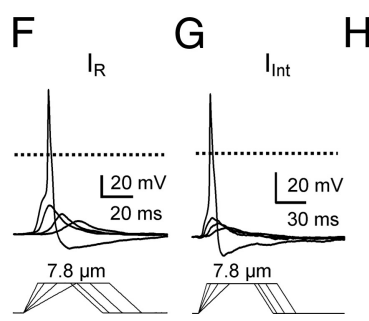

$\mathrm{H}$

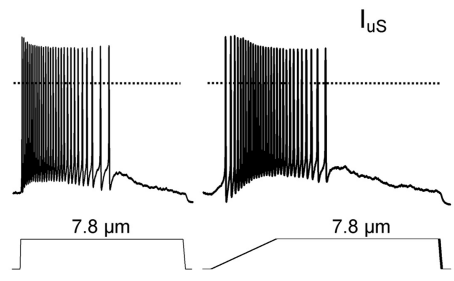

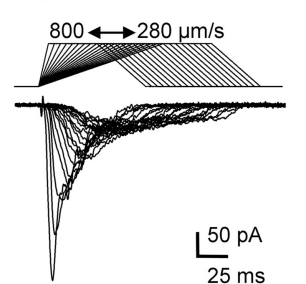

$25 \mathrm{~ms}$
C

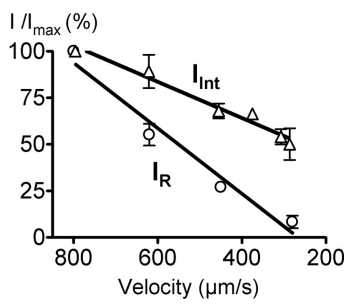

$\mathrm{E}$

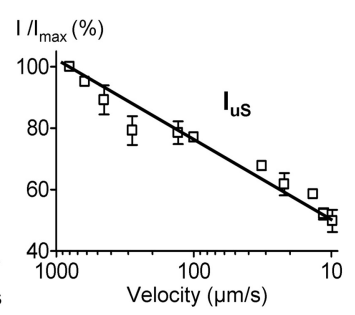

Figure 8. Mechanotransducer current desensitization serves to encode speed and duration of mechanical stimulus in cutaneous sensory neurons. $A, B$, Effects of varying the rate of onset mechanical stimulus on $I_{R}(A)$ and $I_{\operatorname{lnt}}(B)$. C, Normalized $I_{R}$ (circles) and $I_{\operatorname{lnt}}$ (triangles) were plotted as a function of stimulus velocity. A linear regression was fitted to the data, giving a slope of 0.17 and 0.09 $s / \mu \mathrm{m}$ for $I_{R}$ and $I_{\text {Int, }}$ respectively $(n=5-7) . D, I_{\text {uS }}$ was evoked by a mechanical stimulus having a rate of onset ranging from 800 to $10 \mu \mathrm{m} / \mathrm{s}$. $\boldsymbol{E}$, Normalized $I_{\text {us }}$ plotted as a function of stimulus velocity on semilogarithmic axes $(n=8)$. $\boldsymbol{F}$, Velocity-related firing property of an $/ I_{R}$-expressing neuron. Four velocities $(800,554,341$, and $216 \mu \mathrm{m} / \mathrm{s})$ of probe displacement are shown. $G$, Velocityrelated firing property of an $I_{\text {Int }}$-expressing neuron. Four velocities $(800,554,341$, and $216 \mu \mathrm{m} / \mathrm{s})$ of probe displacement are shown. $\boldsymbol{H}$, Representative response of an $I_{u s}$-expressing neuron at three different velocities $(420,5$, and $2 \mu \mathrm{m} / \mathrm{s})$ of probe displacement. All neurons were identified by Dil labeling after hindpaw injection.

there are differences between subpopulations of DRG neurons with respect to the functional properties of mechanotransducer channels. The molecular basis of these mechanotransducer channels has yet to be defined.

\section{Mechanisms of relaxation}

and desensitization of mechanotransducer currents

Our data show that MS channel gating in sensory neurons depends on both the force exerted and the sensitivity of that force. In the most common interpretation derived from hair cell transduction, channel opening occurs when tension stretches the channel gating spring, an elastic element in series with the channel (Gillespie and Müller, 2009; Hu et al., 2010). As the mechanical stimulus is maintained, the free energy of the channel decreases and the channel activity is no longer sustained. This mechanism, that we called here relaxation, can be seen as a decay of MS current during a maintained mechanical stimulus. At variance with a recent report (Rugiero et al., 2010), our data demonstrate that adaptation is a key regulatory process of MS current amplitude. Because adapted MS channels could be reactivated instantaneously after relaxation, the channels were not inactivated but their gating sensitivity had changed as the result of application of the conditioning step. Adaptation therefore can be described operationally as a simple translation of the activa- tion curve of the transducer along the stimulus axis. This may result from a relaxation of tension in the linkage between the swing of the gate of the channel and the tension-sensing element and may be mediated by conformational rearrangements in the channel protein itself or in molecules in series with the tensionsensing element and connecting the channel to the cytoskeleton or lipids (Fig. $9 A, B)$.

A substantial fraction of MS current, however, could not be reactivated after mechanical stimulation, indicating that some channels had inactivated. Therefore, both inactivation and adaptation act concurrently to reduce MS currents. These two mechanisms are common to all MS currents identified here, suggesting that a related physicochemical element determines the properties of MS channels. Nevertheless, adaptation and inactivation showed different mechanical dependencies. Adaptive shift occurred without the need for MS channels to open, whereas inactivation (either fast or slow) seemed to proceed once channels had opened. Consequently, for stimuli that elicit halfmaximal responses, relaxation is dominated by adaptation, whereas for stimuli eliciting saturating responses, relaxation is dominated by inactivation, because the adaptive shift saturates. A model incorporating these assumptions replicates MS channel behavior in the face of a conditioning mechanical stimulus (Fig. 9C). What factors then might be responsible for the different kinetics of MS currents? One possibility is that MS channels are composed of different sets of $\alpha$ subunit isoforms or that the properties are modified by accessory subunits. The local environment of the channels, in particular the membrane lipids, may also differ. Our results do not discriminate between these possibilities.

\section{Modulation of adaptation and inactivation of mechanotransducer currents by voltage}

We found that the rate of MS current relaxation in sensory neurons was almost invariant over the entire range of stimulus intensity. This is clearly different from hair cells, in which fast adaptation is more prominent for moderate stimuli, whereas slow adaptation occurs with larger mechanical displacements (Gillespie and Müller, 2009). In hair cells, also, fast and slow adaptations are mediated by different mechanisms involving $\mathrm{Ca}^{2+}$ and myosin proteins (Gillespie et al., 1993; Lumpkin and Hudspeth, 1995; Ricci et al., 1998; Vollrath et al., 2007; Gillespie and Müller, 2009). In contrast, our data provides evidence that adaptation in sensory neurons operates via a $\mathrm{Ca}^{2+}$-independent route, in agreement with Rugiero et al. (2010).

An intriguing feature of relaxation was its voltage dependence. Relaxation was more pronounced at negative voltages near resting potential and becomes progressively less evident at more depolarized potentials. Depolarization-induced slowing in relaxation kinetics was observed for the four types of MS cur- 
rents investigated and was associated with an alteration in both adaptation and inactivation kinetics. Adaptation is also substantially reduced with depolarization in hair cells, an effect that has been explained, at least in part, by changes in the driving force on $\mathrm{Ca}^{2+}$ entry (Assad et al., 1989; Crawford et al., 1989, 1991; Hacohen et al., 1989; Martinac, 2004). The present data, however, show that $\mathrm{Ca}^{2+}$ had no effects on the voltage dependence of relaxation, suggesting that the channel molecule itself or another closely associated subunit is intrinsically voltage sensitive, as suggested for MS channels in other systems (Gustin et al., 1988; Hamill and McBride, 1992; Suchyna et al., 2004; Akitake et al., 2005; Hamill, 2006).

\section{Mechanotransducer desensitization contributes to firing adaptation}

Current-clamp experiments demonstrate that there is a marked difference in firing response between DRG neurons expressing rapid or slow MS currents. $I_{\mathrm{R}^{-}}$and $I_{\mathrm{Int}^{-}}{ }^{-}$ expressing neurons give a brief AP discharge in response to a ramp and hold stimulus, whereas $I_{\mathrm{S}^{-}}$and $I_{\mathrm{us}}$-expressing neurons instead respond by more sustained AP discharge. Importantly, these differences were attributable to mechanical factors because electrical stimulation could not mimic mechanically evoked firing adaptation in these cells. Although relationship between in vitro and in vivo data remains speculative, the reported results support the view that $I_{\mathrm{us}}$ plays a critical role in generating sustained activities of nociceptors in vivo. Conversely, $I_{\mathrm{R}}$ current appears best suited to shape the phasic discharges of LTMs associated with innocuous touch, although firing pattern in vivo depends also on other factors, including support cells and specialized terminal structures. In addition, it is tempting to speculate that the refractory period of $I_{\mathrm{R}}$ channels produced when high-intensity stimuli are administered may be responsible for the long-lasting depression of LTMs seen after sustained noxious mechanical stimulation of the skin (Adriaensen et al., 1984; Handwerker et al., 1987). Mechanical refractory period of $I_{\mathrm{R}}$ channels can therefore be envisioned as a filtering mechanism of nociceptive stimuli by non-nociceptive fibers.

Finally, our study shows that gating dynamics of MS channels plays a critical role in stimulus representation. The rapid relaxation of $I_{\mathrm{R}}$, and to a lesser degree of $I_{\text {Int }}$, by competing with activation, controls the net amplitude of MS currents. $I_{\mathrm{R}}$ channels respond in full when stimulated by a pressure applied abruptly but are essentially inactive during slowly applied or static forces. The quick reaction to an abrupt stimulus and dumping of slowly applied forces indicate that $I_{\mathrm{R}}$ and $I_{\text {Int }}$ channels respond as velocity detectors. This property is important for detecting small changes in the dynamic stimulus parameters. Adaptation also acts as a mechanism that preserves the instantaneous sensitivity
B
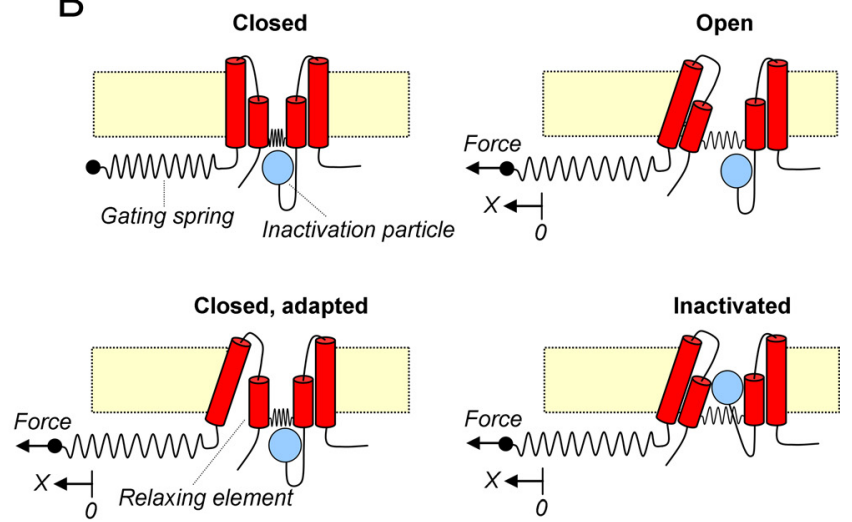

$\mathrm{C}_{2}$

Effect of conditioning on net simulated MS current

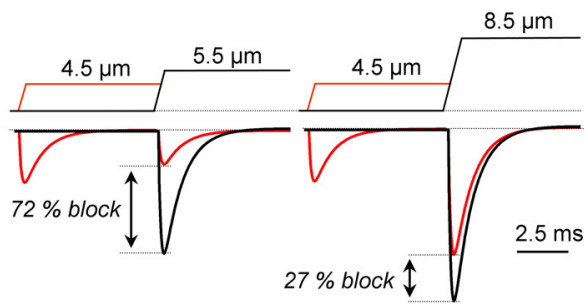

Figure 9. Model for desensitization of mechanotransducer channels in sensory neurons. $\boldsymbol{A}$, Kinetics scheme of MS channel transitions. Applied force favors transition from the closed state $(C)$ to the closed adapted $\left(C_{A}\right)$ state, followed by the open $(0)$ and

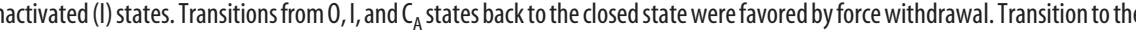
the channel protein. During adaptation, the stiffness of the gating spring remains constant but the channel collapses into a closed showing the position of the activation curve of $I_{\mathrm{R}}$ if a conditioning step of $4.3 \mu \mathrm{m}$ causes a shift of the $I_{\mathrm{R}}(X)$ relation of $1 \mu \mathrm{m}$ and a decrease in conductance of $25 \%$. The probability of the channel being open is given by $I / I_{\max }=1 /\left(1+\exp \left[\left(\operatorname{Stim}_{50}-S \operatorname{sim}\right) / k\right]\right)$. Stim $_{50}$ and $k$ were $5 \mu \mathrm{m}$ and 0.7 for the control (non-adapted) curve and $6 \mu \mathrm{m}$ and 0.7 for the adapted curve. $\boldsymbol{C}_{2}$, Corresponding MS currents. Note the difference in current reduction for moderate and large mechanical stimuli.

of the MS channels. The adaptive shift serves to reset the conductance of the transduction channel toward the resting value, restoring sensitivity during a static stimulus that could potentially saturate transduction. This instantaneous sensitivity of MS channels befits their role in detecting small changes of the stimulus and suited them to encode acceleration and vibration. The fact that $I_{\mathrm{R}}$ and $I_{\text {Int }}$ currents are predominant in putative LTMs favors the view that their kinetics properties are adapted to encode the dynamic features of the stimulus, so critical in innocuous mechanosensation. Conversely, after a gradual change of pressure, only $I_{\mathrm{S}}$ and $I_{\mathrm{uS}}$ channels would be activated and capable of carrying tonic signals typical of nociceptive responses. Thus, our data show that sensory neurons in vitro retain many properties of mechanosensory nerve fibers in vivo and display MS currents with properties that are suited to encode important parameters of the mechanical stimulus.

Collectively, our data indicate that desensitization of MS currents appears to be a critical aspect of afferent signal generation in the sensory system. The difference in desensitization rate relates 
to the functions of MS channels as sensors for phasic or tonic stimuli and enables sensory neurons to achieve efficient stimulus representation.

\section{References}

Adriaensen H, Gybels J, Handwerker HO, Van Hees J (1984) Nociceptor discharges and sensations due to prolonged noxious mechanical stimulation: a paradox. Hum Neurobiol 3:53-58.

Akitake B, Anishkin A, Sukharev S (2005) The "dashpot" mechanism of stretch-dependent gating in MscS. J Gen Physiol 125:143-154.

Assad JA, Hacohen N, Corey DP (1989) Voltage dependence of adaptation and active bundle movement in bullfrog saccular hair cells. Proc Natl Acad Sci U S A 86:2918-2922.

Basbaum AI, Bautista DM, Scherrer G, Julius D (2009) Cellular and molecular mechanisms of pain. Cell 139:267-284.

Coste B, Osorio N, Padilla F, Crest M, Delmas P (2004) Gating and modulation of presumptive NaV1.9 channels in enteric and spinal sensory neurons. Mol Cell Neurosci 26:123-134.

Coste B, Crest M, Delmas P (2007) Pharmacological dissection and distribution of NaN/Nav1.9, T-type $\mathrm{Ca}^{2+}$ currents, and mechanically activated cation currents in different populations of DRG neurons. J Gen Physiol 129:57-77.

Crawford AC, Evans MG, Fettiplace R (1989) Activation and adaptation of transducer currents in turtle hair cells. J Physiol 419:405-434.

Crawford AC, Evans MG, Fettiplace R (1991) The actions of calcium on the mechano-electrical transducer current of turtle hair cells. J Physiol 434:369-398.

Drew LJ, Wood JN, Cesare P (2002) Distinct mechanosensitive properties of capsaicin-sensitive and -insensitive sensory neurons. J Neurosci 22:RC228(1-5).

Drew LJ, Rohrer DK, Price MP, Blaver KE, Cockayne DA, Cesare P, Wood JN (2004) Acid-sensing ion channels ASIC2 and ASIC3 do not contribute to mechanically activated currents in mammalian sensory neurones. J Physiol 556:691-710.

Drew LJ, Rugiero F, Cesare P, Gale JE, Abrahamsen B, Bowden S, Heinzmann S, Robinson M, Brust A, Colless B, Lewis RJ, Wood JN (2007) Highthreshold mechanosensitive ion channels blocked by a novel conopeptide mediate pressure-evoked pain. PLoS One 6:e515.

Eatock RA, Corey DP, Hudspeth AJ (1987) Adaptation of mechanoelectrical transduction in hair cells of the bullfrog's sacculus. J Neurosci 7:2821-2836.

Fettiplace R, Hackney CM (2006) The sensory and motor roles of auditory hair cells. Nat Rev 7:19-29.

Gillespie PG, Müller U (2009) Mechanotransduction by hair cells: models, molecules, and mechanisms. Cell 139:33-44.

Gillespie PG, Wagner MC, Hudspeth AJ (1993) Identification of a $120 \mathrm{kd}$ hair-bundle myosin located near stereociliary tips. Neuron 11:581-594.

Gustin MC, Zhou XL, Martinac B, Kung C (1988) A mechanosensitive ion channel in the yeast plasma membrane. Science 242:762-765.

Hacohen N, Assad JA, Smith WJ, Corey DP (1989) Regulation of tension on hair-cell transduction channels: displacement and calcium dependence. J Neurosci 9:3988-3997.

Hamill OP (2006) Twenty odd years of stretch-sensitive channels. Pflugers Arch 453:333-351.

Hamill OP, McBride DW Jr (1992) Rapid adaptation of single mechanosensitive channels in Xenopus oocytes. Proc Natl Acad Sci U S A 89:7462-7466.

Handwerker HO, Anton F, Reeh PW (1987) Discharge patterns of afferent cutaneous nerve fibers from the rat's tail during prolonged noxious mechanical stimulation. Exp Brain Res 65:493-504.

Holt JR, Corey DP (2000) Two mechanisms for transducer adaptation in vertebrate hair cells. Proc Natl Acad Sci U S A 97:11730-11735.

Hu J, Lewin GR (2006) Mechanosensitive currents in the neurites of cultured mouse sensory neurones. J Physiol 577:815-828.

Hu J, Chiang LY, Koch M, Lewin GR (2010) Evidence for a protein tether involved in somatic touch. EMBO J 29:855-867.

Lumpkin EA, Caterina MJ (2007) Mechanisms of sensory transduction in the skin. Nature 445:858-865.

Lumpkin EA, Hudspeth AJ (1995) Detection of $\mathrm{Ca}^{2+}$ entry through mechanosensitive channels localizes the site of mechanoelectrical transduction in hair cells. Proc Natl Acad Sci U S A 92:10297-10301.

Maingret F, Coste B, Padilla F, Clerc N, Crest M, Korogod SM, Delmas P (2008) Inflammatory mediators increase Nav1.9 current and excitability in nociceptors through a coincident detection mechanism. J Gen Physiol 131:211-225.

Martinac B (2004) Mechanosensitive ion channels: molecules of mechanotransduction. J Cell Sci 117:2449-2460.

McCarter GC, Levine JD (2006) Ionic basis of a mechanotransduction current in adult rat dorsal root ganglion neurons. Mol Pain 2:28.

McCarter GC, Reichling DB, Levine JD (1999) Mechanical transduction by rat dorsal root ganglion neurons in vitro. Neurosci Lett 273:179-182.

Ricci AJ, Wu YC, Fettiplace R (1998) The endogenous calcium buffer and the time course of transducer adaptation in auditory hair cells. J Neurosci 18:8261-8277.

Rugiero F, Wood JN (2009) The mechanosensitive cell line ND-C does not express functional thermoTRP channels. Neuropharmacology 56:11381146.

Rugiero F, Drew LJ, Wood JN (2010) Kinetic properties of mechanically activated currents in spinal sensory neurons. J Physiol 588:301-314.

Suchyna TM, Tape SE, Koeppe RE 2nd, Andersen OS, Sachs F, Gottlieb PA (2004) Bilayer-dependent inhibition of mechanosensitive channels by neuroactive peptide enantiomers. Nature 430:235-240.

Tsunozaki M, Bautista DM (2009) Mammalian somatosensory mechanotransduction. Curr Opin Neurobiol 19:362-369.

Vollrath MA, Kwan KY, Corey DP (2007) The micromachinery of mechanotransduction in hair cells. Annu Rev Neurosci 30:339-365.

Wetzel C, Hu J, Riethmacher D, Benckendorff A, Harder L, Eilers A, Moshourab R, Kozlenkov A, Labuz D, Caspani O, Erdmann B, Machelska H, Heppenstall PA, Lewin GR (2007) A stomatin-domain protein essential for touch sensation in the mouse. Nature 445:206-209. 